Florida International University

FIU Digital Commons

FIU Electronic Theses and Dissertations

University Graduate School

$11-12-2013$

\title{
The Relationship between the Use of Academic Text Talk and the Comprehension of Scientific Academic Language for Diverse Second Graders
}

Peggy Lee Mandel

Florida International University, pmand001@fiu.edu

DOI: $10.25148 /$ etd.FI13120906

Follow this and additional works at: https:// digitalcommons.fiu.edu/etd

Part of the Bilingual, Multilingual, and Multicultural Education Commons, Curriculum and Instruction Commons, Educational Assessment, Evaluation, and Research Commons, Educational Methods Commons, Elementary Education and Teaching Commons, and the Science and Mathematics Education Commons

\section{Recommended Citation}

Mandel, Peggy Lee, "The Relationship between the Use of Academic Text Talk and the Comprehension of Scientific Academic Language for Diverse Second Graders" (2013). FIU Electronic Theses and Dissertations. 1006.

https://digitalcommons.fiu.edu/etd/1006 


\section{FLORIDA INTERNATIONAL UNIVERSITY}

Miami, Florida

THE RELATIONSHIP BETWEEN THE USE OF ACADEMIC TEXT TALK AND

THE COMPREHENSION OF SCIENTIFIC ACADEMIC LANGUAGE FOR

DIVERSE SECOND GRADERS

A dissertation submitted in partial fulfillment of

the requirements for the degree of

DOCTOR OF EDUCATION

in

CURRICULUM AND INSTRUCTION

by

Peggy Lee Mandel

2013 
To: Dean Delia C. Garcia

College of Education

This dissertation, written by Peggy Lee Mandel, and entitled The Relationship between the Use of Academic Text Talk and the Comprehension of Scientific Academic Language for Diverse Second Graders, having been approved in respect to style and intellectual content, is referred to you for judgment.

We have read this dissertation and recommend that it be approved.

Lynne Miller

George O'Brien

Paulette Johnson

Joyce Fine, Major Professor

Date of Defense: November 12, 2013

The dissertation of Peggy Lee Mandel is approved:

Dean Delia C. Garcia

College of Education

Dean Lakshmi N. Reddi

University Graduate School

Florida International University, 2013 


\section{DEDICATION}

I dedicate this dissertation to my family; to my husband Aron, my soul mate, for his encouragement and confidence in my ability, our children David and Rina, for their inspiration and support, and my parents, Hap and Bess, for instilling a love of learning and the knowledge that anything is possible. Without my family's patience, understanding, and love, the completion of this work would not have been possible. 


\section{ACKNOWLEDGMENTS}

I want to thank Dr. Joyce Fine, my Major Professor, for her direction, and recognize the countless hours we worked together. I want to thank the members of my committee, Dr. Lynne Miller, Dr. George O’Brien, and Dr. Paulette Johnson, for their guidance. I want to thank Dr. Bliss for her review and feedback. I want to thank my principal, Dr. Maria Rodriguez, and all the teachers and students in my school who helped me complete this study for their help and cooperation. I also want to acknowledge my colleagues at Florida International University for their support and collaboration as we traveled this academic journey together. 


\section{ABSTRACT OF THE DISSERTATION \\ THE RELATIONSHIP BETWEEN THE USE OF ACADEMIC TEXT TALK AND THE COMPREHENSION OF SCIENTIFIC ACADEMIC LANGUAGE FOR DIVERSE SECOND GRADERS \\ by \\ Peggy Lee Mandel}

Florida International University, 2013

Miami, Florida

Professor Joyce Fine, Major Professor

Changing demographics impact our schools as children come from more linguistically and culturally diverse backgrounds. The various social, cultural, and economic backgrounds of the students affect their early language learning experiences which expose them to the academic language needed to succeed in school. Teachers can help students acquire academic language by introducing words that are within their Zone of Proximal Development and increasing exposure to and use of academic language. This study investigated the effects of increasing structured activities for students to orally interact with informational text on their scientific academic language development and comprehension of expository text.

The Academic Text Talk activities, designed to scaffold verbalization of new words and ideas, included discussion, retelling, games, and sentence walls. This study also evaluated if there were differences in scientific language proficiency and comprehension between boys and girls, and between English language learners and native English speakers. 
A quasi-experimental design was used to determine the relationship between increasing students' oral practice with academic language and their academic language proficiency. Second graders $(n=91)$ from an urban public school participated in two science units over an 8 week period and were pre and post tested using the Woodcock Muñoz Language Survey-Revised and vocabulary tests from the National Energy Education Project. Analysis of covariance was performed on the pre to post scores by treatment group to determine differences in academic language proficiency for students taught using Academic Text Talk compared to students taught using a text-centered method, using the initial Florida Assessment for Instruction in Reading test as a covariate. Students taught using Academic Text Talk multimodal strategies showed significantly greater increases in their pre to posttest means on the Woodcock Muñoz Language Survey-Revised Oral Language Totals and National Energy Education Development Project Vocabulary tests than students taught using the text-centered method, $p \mathrm{~s}<.05$. Boys did not show significantly greater increases than girls, nor did English language learners show significantly greater increases than the native English speakers.

This study informs the field of reading research by evaluating the effectiveness of a multimodal combination of strategies emphasizing discourse to build academic language. 


\section{TABLE OF CONTENTS}

CHAPTER

PAGE

Chapter 1 INTRODUCTION .........................................................

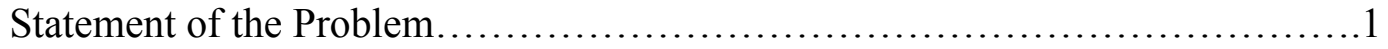

Statement of the Purpose ..................................................... 6

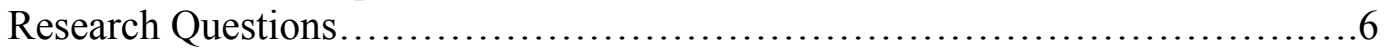

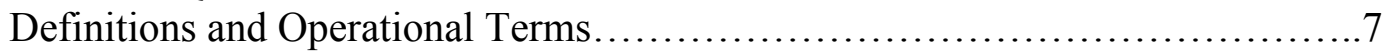

Theoretical Framework .............................................................................12

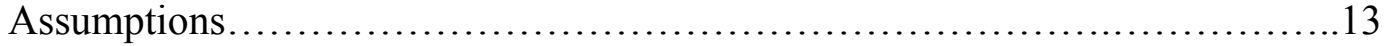

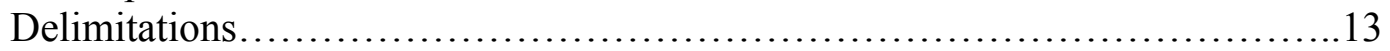

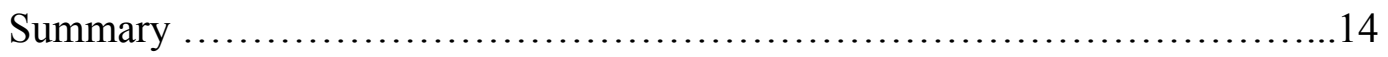

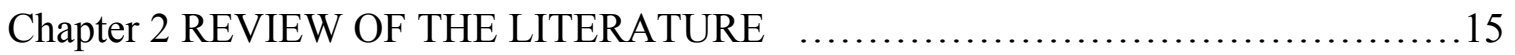

Vocabulary and Language Development ....................................16

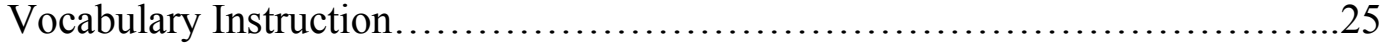

Special Needs of English Language Learners ...............................28

Using Informational Text................................................. 32

Multimodal Active Learning and Oral Engagement ..........................38

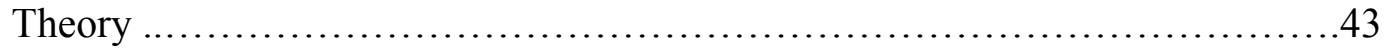

Review of the Literature on the Instruments ...............................44

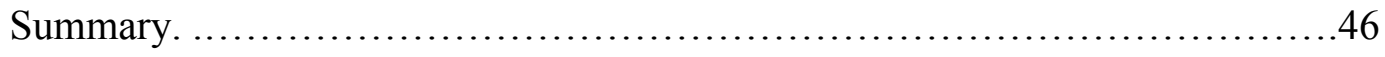

Chapter 3 METHODS AND PROCEDURES ….................................48

Research Questions/General and Specific Hypotheses .........................48

Participants and Sampling Procedures ......................................51

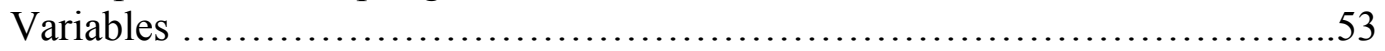

Research Design................................................... 54

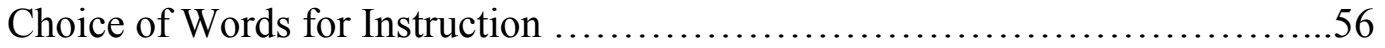

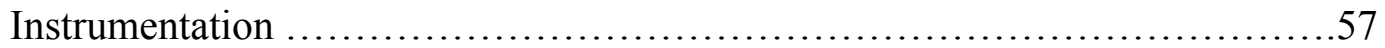

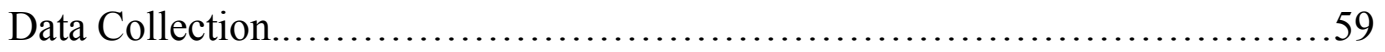

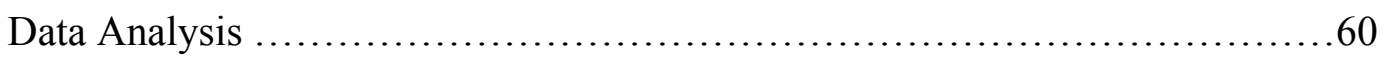

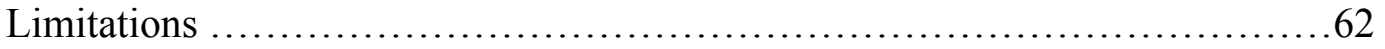

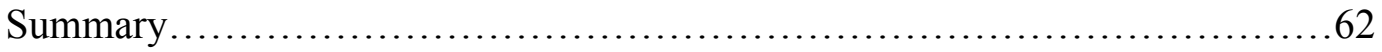

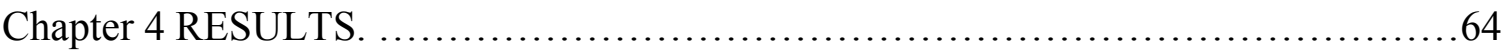

Research Question One....................................................67

Research Question Two ............................................ 70

Research Question Three ............................................. 72

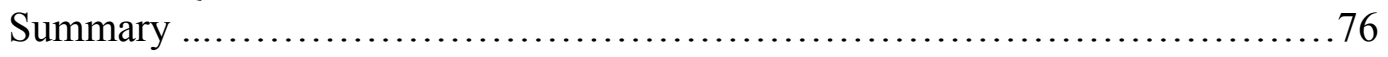

Chapter 5 SUMMARY, CONCLUSIONS, and IMPLICATIONS .....................77

Statement of the Procedures............................................. 78

Research Questions and Specific Research Hypotheses..........................79

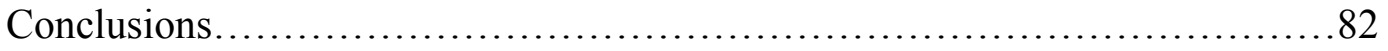




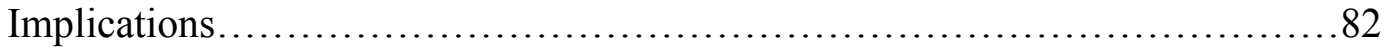

Discussion........................................................... 83

Recommendations for Further Research................................83

REFERENCES ............................................................. 87

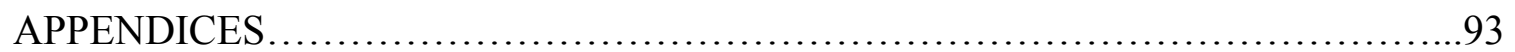

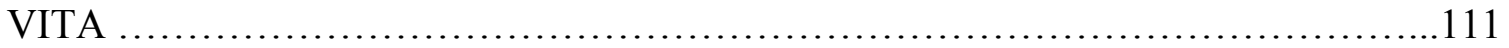




\section{LIST OF TABLES}

TABLE

PAGE

1. Frequencies of Sex and English Language Learner Status by Group..................66

2. Pre Means on the FAIR, WMLS-R Oral W, WMLS-R Comprehension W, NEEDS

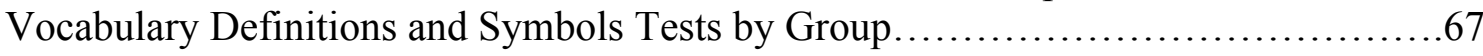

3. Mean Increases from Pre to Post on WMLS-R Oral W and WMLS-R Comprehension W by Group Adjusted for FAIR Vocabulary Assessment..........................68

4. Mean Increases from Pre to Post on NEEDS Definitions and NEEDS Symbols by Group Adjusted for FAIR Vocabulary Assessment..............................70

5. Mean Increases from Pre to Post on WMLS Oral W and WMLS-R Comprehension W by Group and Sex Adjusted for FAIR Vocabulary Assessment.................... 71

6. Mean Increases from Pre to Post on NEEDS Definitions and Symbols by Group and Sex Adjusted for FAIR Vocabulary Assessment................................ 72

7. Mean Increases from Pre to Post on WMLS Oral W and WMLS-R Comprehension W by Group and English Language Learner Status Adjusted for FAIR Vocabulary Assessment

8. Mean Increases from Pre to Post on NEEDS Definitions and Symbols by Group and English Language Learner Status Adjusted for FAIR Vocabulary Assessment.......... 75 


\section{CHAPTER 1 \\ INTRODUCTION}

Many students, especially young English language learners (ELLs), have difficulty comprehending content area text. Various factors contribute to this struggle. They may have difficulty with content area reading because their prior experience offered limited exposure to academic language (Nagy \& Scott, 2000) and as a result, the vocabulary is unfamiliar and the text structure is difficult (Duke \& Bennett-Armistead, 2003; Wong-Filmore \& Snow, 2002). They may lack sufficient background knowledge needed to grasp new concepts and acquire new vocabulary. Even though they may be able to communicate with their friends using standard, everyday English, they may not be orally proficient in academic English which makes it difficult for them to express their understanding in school. Academic English is the language students are likely to encounter at school listening to teachers, reading textbooks, and taking tests. This study investigated the effects of multimodal, context-embedded learning experiences designed to increase diverse second graders' oral practice with academic language on their acquisition of scientific academic language and reading comprehension.

In this chapter, following a brief introduction to the topic, the problem statement, purpose of the study, and research questions are presented. Chapter 1 also includes definitions and operational terms, theoretical framework, assumptions underlying the study, and delimitations.

\section{Statement of the Problem}

The primary goal of reading is comprehension. A well-developed vocabulary is needed for full comprehension (Beck, McKeown, \& Kucan, 2002, Nagy, 2003). 
Knowledge about the topic of a text, domain knowledge, is also critical for comprehension (Pressley, 2000). Informational text and science text, specifically, has a specialized vocabulary and structure. Students need knowledge of technical vocabulary, scientific ideas, and informational text structures to understand and write scientific text (Honig, 2010). Background knowledge is also needed to improve vocabulary, because students need to understand the concepts to connect new words and ideas to their previous experiences. Students need practice with academic language to successfully comprehend content area test (Zwiers, 2005). Active engagement in learning tasks is important for effective vocabulary learning (National Reading Panel, 2000).

A problem is that many students lack opportunities for active engagement with the type of vocabulary needed to succeed in school. Changing demographics impact the schools as children come from more linguistically and culturally diverse backgrounds (Tompkins, 2009). The various social, cultural, and economic backgrounds of the students affect their early language learning experiences which expose them to the academic language needed to succeed in school (Hart \& Risely, 2003). Students, whose home experience has not provided a substantial foundation in vocabulary and academic English, need to accelerate their vocabulary development even faster to catch up with their their peers (Nagy \& Scott, 2000). Without the benefits of oral practice, these students may struggle with academic language and have difficulty comprehending expository text. Teachers educating students from diverse linguistic backgrounds need to assess the students' prior knowledge and implement strategies to help all students attain sufficient language experience needed to successfully comprehend content area text (Helman, 2009). 
Informational books are excellent for building background knowledge because students learn about real topics that are familiar and relevant to their lives. Introducing informational books to students at a young age also exposes them to the language and structure of academic language found in nonfiction text which may help build vocabulary and other kinds of literacy knowledge (Duke \& Bennett-Armistead, 2003).

Language is a tool that teachers can use to enhance cognitive development (Costa $\&$ Marzano, 1987). Teaching and learning are accomplished through the use of language and the daily exchange of words in a classroom. This language creates the classroom culture, defined as the set of important understandings that class members share (Costa \& Marzano, 1987). Students' word knowledge plays a critical role in their academic success (Tompkins, 2009). The cognitive language found in school, in informational books and expository text, is an extremely important factor in school success (WongFilmore \& Snow, 2002). This language, referred to as the language of thinking by Costa and Marzano (1987), is essential because of the characteristic of labeling. When people create a name or a label for something, they also create a reality that did not exist for them previously. We structure our perceptions when we create labels, and new labels foster new perceptions. When we use words to describe thinking processes, such as compare, contrast, predict, infer, analyze, we are teaching the students to do very specific types of thinking. Developing a successful program for teaching thinking, especially important in science, is dependent upon developing a classroom language of conditions that involves the use of specific cognitive terminology and shows students how to perform particular skills. As the students hear specific terms they develop the cognitive 
processes that these labels signify, internalize the words, and use them as part of their own vocabularies (Costa \& Marzano, 1987).

Engaging the children in active learning is fundamental to Lev Vygotsky's theory of cognitive development. His socio-cultural approach to learning emphasizes the social factors and the role of language in cognitive development (Mcleod, 2007). Children develop oral language first as the means for learning both in school and out of school. Oral language functions as a foundation for literacy (Wong Fillmore, \& Snow, 2002). Oral vocabulary is important to the development of reading vocabulary because almost all early reading is based on oral language (National Reading Panel, 2000). Having vocabulary in the oral language helps the reader make the translation of print to speech more meaningful. Many students with insufficient practice in oral academic language are missing this critical step in their academic language development.

A recent study by Wasik, Bond, and Hindeman (2006), on the effects of a language and literacy intervention with Head Start children from high-poverty homes showed significant increases in the size of the children's vocabularies when they had appropriate opportunities to learn. Children in the intervention classrooms engaged in conversations, expressed and elaborated on their ideas, feelings, and reactions to stories and activities. The findings of the Head Start Study suggest that interventions to increase the amount of talk can have positive effects on the children's vocabularies, and conversations with the children both during and outside of book reading are positively related to children's language development.

Beck and McKeown (2001) developed a strategy that supported students' development of vocabulary following read-alouds with open questions and discussion. 
Building upon their research, meaningful talk about informational books could actively involve children in using new vocabulary to discuss new concepts. This can be accomplished using read-alouds, retellings, sentence frames on word walls, word games, and writing activities. Retelling helps students recognize features of informational text and remember key points (Moss, 2004). Sentence walls assist the students in identifying the structure of academic language (Carrier \& Tatum, 2006). Word games (Padak \& Rasinski, 2009) and rhymes (Burn, 2011) help children learn to say and remember new vocabulary and ideas. Providing opportunities for student discourse about their reading helps students verbalize their thinking and develop confidence in discussing ideas. In addition, writing activities support students in becoming proficient in academic vocabulary (Honig, 2010).

Teachers face many challenges in planning and providing time for oral practice including getting appropriate training, meeting curriculum requirements, and working within time restraints. Most early vocabulary studies with young children have focused on storybook readings which contain different language and narrative structure (Duke \& Bennett-Armistead, 2003). In this study, students participated in oral practice with academic vocabulary by using sentence walls, participating in learning games and chants, retelling informational passages, and other academic exercises designed to increase personal experience with academic language.

This study investigated the effects of increasing opportunities for students to orally practice scientific academic language by participating in multimodal, contextembedded activities designed to scaffold children's use of oral academic vocabulary. Results suggest that increasing exposure to informational text and increasing oral practice 
can benefit student's acquisition of academic language and increase comprehension. This study adds to the research that is needed to understand how young children learn from informational text, and the research results are beneficial to both teachers and students wanting to improve academic language proficiency.

\section{Statement of the Purpose}

The purpose of this study was to investigate the effects of increasing structured activities for students to orally interact with informational text on their academic language development and comprehension of expository text. This study was based on the premise that early exposure to informational text, combined with increased opportunities to orally practice with the language and structure of informational text, would be beneficial to young diverse students' comprehension of scientific text.

The activities in this study, which focused on informational text and were designed to scaffold verbalization of new words and ideas, are referred to as Academic Text Talk. Academic Text Talk activities were designed to increase students' oral practice with scientific academic language, and help students achieve scientific academic language proficiency necessary for them to express their understanding of concepts and realize greater comprehension.

\section{Research Questions}

The research questions for this study were developed to assess the effects of Academic Text Talk on the comprehension of scientific academic language for diverse second graders. The research questions are as follows: 
1. Is there a difference in the scientific academic language proficiency between the students who are instructed using Academic Text Talk as compared to students who are instructed using a text-centered method?

2. Is there a difference in the scientific academic language proficiency by treatment (Academic Text Talk, text-centered) and sex for the students?

3. Is there a difference in the scientific academic language proficiency by treatment and English language status (English language learners, native English speakers) for the students?

\section{Definitions and Operational Terms}

\section{Academic Language}

Academic vocabulary consists of words that students are likely to encounter at school when listening to teachers, reading textbooks, and taking tests. Defined by Zwier (2004), academic language consists of the set of words and phrases that (a) describe content-area knowledge and procedures, (b) express complex thinking processes and abstract concepts and (c) create cohesion and clarity in written and oral discourse. For the purposes of this study, academic language was measured by performance on the Woodcock-Muñoz Language Survey-Revised (WMLS-R). 


\section{Academic Text Talk}

Multi-modal, context-embedded learning experiences focused on informational text and designed to scaffold verbalization of new words and ideas to accelerate the development of diverse students' academic language and comprehension.

\section{Annual Measurable Achievement Objectives (AMAO)}

The Federal No Child Left Behind Act requires that school districts that receive Title III funds are monitored to see if they meet three AMAOs for their English Language Learners as measured by CELLA and FCAT.

\section{Basic Interpersonal Communication Skills (BICS)}

BICS is the form of conversational proficiency that can be developed outside of formal schooling.

\section{Classroom Culture}

The set of important understandings that class members share (Costa \& Marzano, 1987).

\section{Cognitive Academic Language Proficiency (CALP)}

The language proficiency of academic situations that emerges and becomes distinctive with formal schooling. 


\section{Comprehensive English Language Learning Assessment (CELLA)}

Currently the test used in Florida for English language proficiency assessment. English Language Learners in this study are identified as ESOL levels 1, 2, 3, 4 or 5 by this assessment.

\section{Content Area Text}

Science or social science nonfiction, informational text.

\section{English Language Learners (ELLs)}

Students acquiring English as a second language, identified by Miami Dade County Public Schools as measured by using the Comprehensive English Language Learning Assessment (CELLA) test as a measurement tool.

\section{Florida Assessments for Instruction in Reading (FAIR)}

The Florida Department of Education developed this statewide assessment in collaboration with the Florida Center for Reading Research to assess reading, vocabulary, and monitor progress. Scores from the beginning of the year Florida Assessments in Instruction and Reading (FAIR) tests were used to assess ability similarities in groups.

\section{Florida Comprehensive Achievement Test (FCAT)}

The assessment currently used by the state of Florida to measure academic performance. 


\section{Informational Text}

A type of nonfiction (factual) text that varies from other types of nonfiction in purpose, features, and format. The purpose of informational text is to convey information about the natural and social world. Features talk about whole classes of things in a timeless way and may include reference books, and process-informational books (Duke \& Bennett-Armistead, 2003).

\section{Instructional Conversations}

Purposeful or meaningful talk designed to build comprehension and meaning of concepts and vocabulary.

\section{Multi-modal/Multisensory}

Features of instruction that have auditory, visual, and kinesthetic components that are both receptive and productive.

\section{The National Energy Education Development Project (NEED)}

NEED promotes an energy conscious society by creating a network of students, educators, business, government, and community leaders to bring balanced energy programs to schools through teacher development, timely and balanced curriculum materials, supportive program capabilities, and project support. 


\section{Nonfiction Text}

Any text that is factual such as biographies, procedural text, and nonfiction narrative whose primary purpose is something other than to convey information about the natural and social world (Duke \& Bennett-Armistead, 2003).

\section{Oral Language Proficiency}

Oral Language Proficiency includes both receptive and expressive skills and can also encompass knowledge or use of specific aspects of oral language including phonology, vocabulary, morphology, grammar, and discourse features as well as pragmatic skills, and skills in both comprehension and expression (August \& Shanahan, 2008).

\section{Retelling}

Oral or written post reading recalls during which children relate what they remember from reading or listening to a particular text (Moss, 2004).

\section{Scientific Academic Language}

Terms used in the academic language of science, necessary to understand to read and understand science literature.

\section{Sentence Frames}

Structured cloze sentences to model a specific language function appropriate to the text. Sentence walls contain multiple summary frames for common text structures 
such as compare and contrast, description, sequences, problem/solution, cause and effect (Donnelly, W.B. \& Roe, C.J., 2010).

\section{Title III Funds}

Funding from the Federal government to help students who have limited English language proficiency. The No Child Left Behind Act requires that school districts that receive Title III funding are monitored to see if they meet annual objectives which include progress in English language acquisition and proficiency, and attainment of academic standards. Academic language proficiency is needed to achieve these objectives.

\section{Woodcock-Muñoz Language Survey-Revised (WMLS-R)}

A norm-referenced assessment used in this study because it provides a broad sampling of proficiency in oral language, language comprehension, reading and writing and academic language.

\section{Theoretical Framework}

The instructional strategies implemented in this study are constructivist in nature. Constructivist learning theory is the cognitive approach to learning emphasizing the role of the child as an active participant in construction of knowledge, and focusing on children learning from their experience. The constructivist approach stresses active learning, both physically and mentally, for children to construct knowledge of the world around them. Constructivism is based on theories from John Dewey, Lev Vygotsky, Jerome Bruner, and Jean Piaget (Gibbons 2008). Piaget theorized that children's 
development precedes their learning, and emphasized self-initiated discovery. Vygotsky's approach to cognitive development differed from Piaget in that Vygotsky placed more emphasis on social factors, culture, and the role of oral language in the development of higher mental processes (Mcleod, 2007). His concept of the Zone of Proximal Development (ZPD) refers to the difference between what a child can achieve independently and what a child can achieve with guidance and encouragement from a skilled partner (Vygotsky, 1978). Teachers can scaffold a child's learning with guidance and encouragement by facilitating more opportunities for students to interact with academic language. Increased practice helped students become more proficient with academic language, and achieve higher comprehension.

\section{Assumptions}

Several assumptions underlie this study. The facilitation of increased opportunities for students to interact orally on the topics covered in the informational texts are sufficiently generic in their relationship to learning to test the effects of increased academic text talk on scientific academic language proficiency. Second, it is assumed that the demographics (ethnicity, sex, and grade level), as reported by parents and recorded in school records, are sufficiently free of error.

\section{Delimitations}

The students were all second graders in six classrooms in a single selected school who participated in the beginning of the year Florida Assessment in Reading Instruction Vocabulary Test, and completed the pre- and post-tests of the Woodcock Muñoz 
Language Survey- Revised. The sample was delimited to those students who were available for all pre and posttests.

The Instructional treatment period was planned for 8 weeks. The sample was delimited to those students who were available for the length of the instructional treatment.

\section{Summary}

Many young students have difficulty reading and fully comprehending content area text. Their prior learning experiences may not have included exposure to academic language, informational text, or sufficient background knowledge needed to acquire new vocabulary and comprehend scientific concepts. Many may be lacking experience with oral language needed for comprehension. Multimodal, context-embedded activities that stimulate oral discussion of informational text could build background knowledge and provide students with opportunities to orally practice academic language skills using new vocabulary to explore and clarify concepts, leading the way to fuller reading comprehension.

This study was undertaken to determine the relationship between the use of Academic Text Talk, a combination of multimodal context-embedded activities designed to increase oral practice with scientific academic language, and the comprehension of scientific academic language for diverse second graders. 


\section{CHAPTER 2}

\section{REVIEW OF THE RELATED LITERATURE}

Chapter 2 contains a review of the literature on factors influencing elementary students' development of vocabulary and academic language necessary for comprehending content area text. The research focuses on the role that oral language plays in academic language development needed for reading comprehension.

The first section concentrates on the importance of vocabulary in learning, and how children develop vocabulary and language. It examines how prior experience, or lack of it, can affect one's ability to learn new vocabulary and concepts. This is especially important in the area of scientific academic language with a more specialized vocabulary. Characteristics of different theories of vocabulary instruction are discussed with an emphasis on academic language in content areas.

The next section explores the special needs of English Language Learners with respect to their development of academic language. Academic language differs from home language and many young students, especially English language learners, lack exposure to vocabulary and academic English language needed to succeed in school. These students rely mainly on school experiences for their academic English language development, which makes it critical that they receive the intervention they need.

The third section explains the rational for using more informational text with young students to build background knowledge and vocabulary, and orally practice with

academic language. Young students learning to read across the content areas need extra 
support in understanding specialized vocabulary, implied concepts, and organizational structures.

Fourth, the benefits of using multimodal, context-embedded learning experiences, Academic Text Talk, are discussed with an emphasis on oral language development for all students who need the extra oral practice to master the scientific academic language needed to fully comprehend informational text.

The concepts of constructivist learning theory and how it supports the use of the activities in the Academic Text Talk treatment are examined next. Then, a review of the literature on the instruments discusses characteristics of vocabulary, oral language, comprehension assessments, and the attributes of the specific assessments selected for this study.

\section{Vocabulary and Language Development}

How do children develop language, and what is the role of oral language in vocabulary and language development? Vocabulary refers to the words we must know to communicate effectively. Vocabulary can be categorized in many different ways depending on the type and the purpose. Receptive vocabulary denotes words understood when others speak or when they are read in text. Productive vocabulary, also called expressive vocabulary, denotes words used in speaking to others or in writing. Most researchers agree that receptive vocabulary is much larger than productive vocabulary because we can recognize words that we rarely use (Pearson, Hiebert, \& Kamil, 2007; NRP, 2000). This is especially true with young children. 
Oral vocabulary refers to the words used in speaking or recognized in listening, and the words used in writing and recognized in reading are considered reading vocabulary. Oral vocabulary plays an important part in learning to read. For young children, words are usually learned first through oral vocabulary (Wong Fillmore, \& Snow, 2002) which makes them easier to comprehend when encountered through reading. Children use the words they have heard to make sense of the words they see in print. The National Reading Panel Report in 2000 stated that when students read, the reading vocabulary they encounter in their texts is mapped onto the oral vocabulary the reader already has. If the written representation is already a known word in the learners' oral vocabulary, letter sound correspondence to print material is more valuable. Meaning is accessed through visual word recognition, but the sound of the word supports the visual information and helps to hold it in memory (Cunningham, 2000). Granted that reading vocabulary is critical for comprehension, oral vocabulary is crucial in making the transition from oral to written forms.

Children learn vocabulary by encountering words repeatedly in many contexts. They need to be immersed in words in a variety of ways and personally involved in constructing word meanings (Blachowicz \& Fischer, 2000). Vocabulary is critical in learning because early vocabulary consistently predicts children's later reading achievement (Cunningham \& Stanovich, 1997). Results from a 2002 longitudinal study designed to clarify the relationship between oral language and early reading development provided evidence that oral language variables other than phonological awareness are predictive of beginning reading for both word-level reading and text comprehension (Roth, Speece, \& Cooper, 2002). 
Children learn much of their vocabulary through incidental learning, hearing words around them in the context of everyday activities. Parental language usage and interactions affect children's vocabulary and usage (Hart and Risely, 2003). Before they go to school, or begin socializing with friends, almost everything children learn comes from their families. The data from an early study on poverty and children's academic growth showed that ordinary families differ immensely in the amount of experience with language and interaction they regularly provide their children. These differences in the children's language experiences are strongly linked to children's language accomplishments at age 3. By the time students are in the second grade, trends in amount of talk, vocabulary growth, and style of interaction are already established (Hart and Risely, 2003).

Research by Cunningham and Stanovich (1995) indicated that if most vocabulary is acquired incidentally, then the only opportunities for students to acquire new word meanings occur when they are exposed to new words in oral or written language that is outside their existing vocabulary. This information supports the importance of increasing children's exposure to richer vocabulary through reading and oral practice.

Children can acquire new words through incidental exposure such as in story book reading. In 2005, Roberts, Jurgens, and Burchinal studied children between 3 and 5 years old to examine how four specific measures of home literacy practices and a global measure of the quality and responsiveness of the home environment during preschool years predicted children's language and emergent literacy skills. The global measure of overall responsiveness and support of the home environment was the strongest predictor of young children's language and literacy skills (Roberts, Jurgens, and Burchinal, 2005). 
Children also learn through reading and incidental exposure to print. Cunningham and Stanovich (1997) completed a 10 year study which linked first, third, and fifth grade reading ability to exposure to print. They studied the reciprocal influence that exposure to print had on the development of cognitive processes and declarative knowledge and found that exposure to print was a reliable predictor of differences in the growth in reading comprehension ability throughout elementary school and beyond (Cunningham \& Stanovich, 1997). The amount of time a child spends reading books is related to the child's reading level in fifth grade and the growth in reading proficiency from second to fifth grade (Anderson, Wilson, \& Fielding, 1988).

Children who grow up with the benefits of access to a variety of reading material benefit by developing greater vocabulary and depth of comprehension. Many children, however, may not have the benefit of a variety of reading materials. Many students may not be read to at all and others may only hear or read fictional storybooks which focus on character, setting, problem and solution formats, or simple beginning, middle, and end sequence. These children will not be familiar with the different text structure of informational text or words and phrases found in academic language.

In one study on the number and type of words in printed school English, researchers hypothesized that the principal force driving vocabulary growth is experience with language (Nagy \& Anderson, 1984). Oral language was cited as especially beneficial for young children because it allows for interaction and feedback. This study showed that the oral language children learn usually contains a smaller proportion of difficult or low frequency words than written language. While oral language may aid children in learning new words when reading, there is typically less exposure to new 
words in oral language as they get older. Nagy and Anderson (1984) propose that at the beginning of third grade the amount of free reading is a greater determining factor of vocabulary growth. However, students need strategies and practice to comprehend new words they encounter in reading, especially with expository text.

The importance of the children's language experiences in their early years cannot be underestimated. The data from Hart and Risely's 1995 study on the differences in children's cumulative experience before age 3 suggests that intervention must address an entire general approach to experience, not just a lack of knowledge or skills. The researchers hold that cognitively, experience is sequential. Experience in infancy establishes habits of seeking, noticing, and incorporating new and more complex experiences, as well as schemas for categorizing and thinking about experiences. The amount and diversity of children's past experience influences which new opportunities for experience they notice and choose (Hart \& Risely, 2003). Knowing that teachers today are challenged with many children having diverse early learning experiences, this study investigates instructional strategies designed to give all children sufficient experience to realize vocabulary and academic growth.

Again, the amount and diversity of children's past experiences affects the type of language they learn. Literacy is viewed in terms of the different sorts of social practices in which it is embedded, and is almost always involved with oral language and with ways of acting, interacting, and thinking (Gee, 2005). Jim Cummins first theorized about the distinction between the types of language spoken socially or at home, and the type of language used in academic settings in 1996. He called social or everyday language Basic Interpersonal Conversational Skills or BICS. This social language has context embedded 
meaning and it has context cues that make it easier to understand. The second type of language he called Cognitive Academic Language Proficiency or CALP. CALP is harder for learners to understand because its context is reduced and more cognitively demanding, and because technical terms, complex sentence structures, and less familiar topics are involved (Tompkins, 2009). The language found in standardized tests is CALP. CALP is the language that helps students succeed in school, which is why it is so important to emphasize building academic vocabulary in content area classes. Limitations in CALP are directly related to difficulties in academic learning (Frances, Rivera, Lesaux, Kieffer, \& Rivera, 2006).

Academic language has been referred to as the language of thinking (Costa \& Marzano, 1987) and the language of learning. Academic vocabulary consists of words that students are likely to encounter at school in reading, classwork, listening to teachers and assessments across all content areas. This language is the tool the teachers use to create a classroom culture by the shared understandings that the students have. Academic language differs from home language in vocabulary and structure. The structure is often organized around concepts such as main idea and details, cause and effect, and sequence. Teachers use this language to enhance cognitive development by using labels to describe concepts and thinking processes students need to use. Examples of words used to describe specific thinking process include compare, contrast, predict, infer, and analyze. Developing a successful program for teaching thinking, especially important in science, is dependent upon developing a classroom language of conditions that involves the use of specific cognitive terminology and shows students how to perform particular skills. As the students hear specific terms they will develop the cognitive processes that these label 
signify, internalize the words, and use them as part of their own vocabularies (Costa \& Marzano, 1987).

It is essential that students trying to understand new concepts know the necessary academic vocabulary necessary to succeed in school. However, few students come to school fully competent in the academic language required for text interpretation and for the kind of reasoned discourse teachers expect (Wong Fillmore \& Snow, 2002). The many students who do not come from academically advantaged backgrounds have little experience with this type of specialized vocabulary.

Problems arise when students don't understand the teachers' expectations about academic discourse patterns. Teachers often begin student interactions by asking questions and evaluating responses, and are often unaware themselves of their expectations for student discourse (Wong Fillmore \& Snow, 2002). However, with explicit knowledge of academic structure and vocabulary, they could have tools to help children understand the expectations associated with academic English.

Different domains of study require specialized vocabulary. For example, people access scientific ideas through language and use theoretical language to mediate scientific concepts in academic settings. Students' success in the domain of science is linked to their fluency with this specialized discourse (Gee, 2005). Being fluent in a language generally refers to one's ability to use the language with speed and accuracy. Being fluent in a specialized language such as scientific discourse involves receptive knowledge and expressive knowledge of linguistic patterns and words (Honig, 2002). 
In general, school literacy is regarded in terms of reading and writing, and there is little focus on specific vocabulary needed for academic success in a field such as science. Even though not all students have experienced enough opportunities to have adequate social and incidental exposure to be familiar with the academic language used in school, especially scientific academic language, they need to learn that academic language often describes higher order thinking processes such as comparing, analyzing, and evaluating (Zwier, 2004). If they are taught to be aware of the concepts and thinking processes associated with scientific vocabulary, they will begin to identity the academic language that describes these thinking skills. To be successful, schools need to focus on the acquisition of academic sorts of language within specific social practices (Gee, 2005).

In her analysis of informational text, Pappas (2006) states that many children have few opportunities to discuss scientific thinking in out-of school contexts, and emphasizes that unless children learn the distinctive language of science, they cannot truly learn science. In the area of science literacy, many parents do not emphasize science literacy because few parents actually experienced activity-based science inquiry in their early schooling or have satisfactory knowledge of basic science concepts (Shymansky, Hand, $\&$ Yore, 2000). For the children of these parents, it is necessary for teachers to provide experiences where the students can actively participate and receive guidance, coaching, and encouragement.

Results from a study on shared family scientific thinking (Crowley et al., 2000) indicate that early experiences affected the ways students think in areas of inquiry, theory building, and scientific connections. The study, designed to investigate the role that parents play in structuring children's everyday scientific reasoning, used transcripts and 
videotapes from an exhibit at a children's science museum to study different types of parent talk. The researchers categorized talk as describing evidence, giving directions, explanations, and other. Findings suggested that children engaged in shared scientific thinking with their parents had greater opportunity to learn than children engaged in scientific thinking with peers or by themselves. Most of the interactions included parent talk about how to generate new kinds of evidence or make direct comparisons between different kinds of evidence. Parents also assumed the role of explainer by connecting the experience to prior knowledge or introducing abstract principles. The children's exploration of evidence was observed to be longer, broader, and more focused on relevant comparisons for children whose parents engaged them with the exhibit, than for those students without parental engagement (Crowley et al., 2000). The findings also suggested that parents often guided children to recognize the most relevant kinds of evidence and help provide constraints for theory building.

Pappas (2008) uses the term "Deficit Theory" to explain students who have deficits because of economic, ethnic, or cultural reasons. These students from diverse backgrounds, affected by socioeconomic or cultural differences, are lacking exposure to vocabulary and experiences which stimulate their approach to learning. This study recognizes the problem that not all children receive support in academic language, evidence collection, and theory construction especially in science. This investigation on the effects of increased practice with oral language is vital for the learners of diverse backgrounds because of the challenge for teachers to identify and implement the most effective strategies to ensure that all students have sufficient opportunities. Also, 
following the research on the importance of early experience, it is vital that we work to reduce this gap while the children are young.

\section{Vocabulary Instruction}

The National Reading Panel (2000) examined the scientific evidence on the effects of vocabulary instruction on reading achievement. Their investigation looked at the literature on vocabulary instruction and the literature on the measurement of vocabulary. Even with clear agreement on the importance of vocabulary and its relationship to reading ability, this report showed that most recent research has been conducted on overall comprehension, and little has been done to clarify the causal link between vocabulary and comprehension. Another finding of the National Reading Panel's analysis of research studies is that there was relatively little research on vocabulary instruction done outside of the third to eighth grade range. Possible explanations included the idea that there is less emphasis on methods in early grades, and the teaching of vocabulary is often not separate from other instruction during these years (NRP, 2000). Data from National Reading Panel research analysis suggest that as students begin to read content material, they need to learn vocabulary specific to the material. The National Reading Panel (2000) stated the need for more research to be done on the link between vocabulary and comprehension with respect to the most effective practices for younger students who are struggling with the language found in content area text.

Research from a recent content analysis investigating vocabulary instruction in Social Studies textbooks for Grades 4-8 suggested that even though publishers realized the importance of vocabulary, most instructional activities focused on more traditional 
approaches such as definitions and fill-in-the-blank exercises. Little student support was given for writing and other higher, generative levels of word processing (Harmon, Hedrick, \& Fox, 2000).

Several studies have shown that pre-instruction of vocabulary can affect reading comprehension because there are fewer unfamiliar concepts in the material to be read. Also, if vocabulary words are in the oral language of the reader, it helps make the translation of print to speech more meaningful (Brett, Rothlein, \& Hurley, NRP, 2000). Yet pre-teaching vocabulary only is not adequate because students need a depth of meaning to truly comprehend (Beck, et al, 2002). Students need multiple exposures to a word and active learning to comprehend meaning. One study showed that teachers acting out or demonstrating the meaning of a vocabulary word was related to vocabulary development (Wasik, Bond, \& Hindman, 2006). Based on the trends discovered in their comprehensive analysis, the National Reading Panel concluded there is no single best method of learning vocabulary and suggested that a variety of direct and indirect methods can be effective. The question arises as to which experiences in combination have the greatest effect on students' achievement.

An analysis of two decades of research on vocabulary instruction by Blachowicz and Fisher (2000) supports the idea of a combination of strategies. Their research suggested four main principles to guide instruction in a variety of contexts. Students should be active in developing their understanding of words and ways to learn them. Students should personalize word learning, be immersed in words, and build on multiple sources of information to learn words through repeated exposures (Blachowicz and Fisher, 2000). 
Blachowicz and Fisher also emphasized the need to adapt instruction for content areas as students are learning new words, new concepts, and multiple meanings. They are learning new words for familiar concepts, new meanings for familiar words used in specialized ways for a particular discipline, as well as encountering words that are both new words and new concepts. In content area learning, the specific meanings for words and concepts are central to instruction and often relate to different types of instructional tasks, so students need to understand the words both receptively and expressively, retain the vocabulary, and use it to scaffold later learning.

A review of Florida's new Next Generation Sunshine State Standards (NGSSS) for second grade revealed vocabulary is the focus of three reading and language art standards that include: the student uses new vocabulary that is introduced and taught directly, categorizes key vocabulary and identifies salient features, and relates new vocabulary to familiar words. These standards are repeated for all grade levels through $12^{\text {th }}$ grade (FDOE).

The NGSSS math standards include interpreting the physical world with geometric shapes and describing it with corresponding vocabulary, and using appropriate vocabulary to compare shapes according to attributes and properties. The need to include vocabulary in the math standards is supported by recent research on spatial thinking which emphasizes the importance of teaching spatial words like outside, under, around, and corner to young children. Results of this recent study indicate that preschool children whose parents use a greater number of spatial words show better growth in spatial thinking (Newcombe, 2010). 
Conversely, in the NGSSS for science, vocabulary was not mentioned. With the importance of science being added to subjects tested by the all-important Florida Comprehensive Achievement Test (FCAT), and the necessity of understanding the specific vocabulary of science for full comprehension, why isn't there more emphasis on the development of vocabulary and scientific academic language?

The rising need for accountability in school systems adds pressure for schools to improve student standardized performance. Between $70-80 \%$ of standardized reading test content is expository (Daniels, 2002) so it seems essential to provide students with the tools necessary to develop understanding of informational text (Moss, 2004).

What prevents teachers from spending more time on vocabulary instruction, especially with younger students? One explanation is that time and curriculum restraints play a role. Early learning does take place through oral contexts, but as children get older and progress in school, the tendency is to rely less on oral language. Students are often are left to try to comprehend difficult content area text independently. The problem with written context for many students is that it lacks features such as intonation, body language, and shared physical surroundings that help children learn new vocabulary (Beck, McKeown, \& Kucan, 2002). The recurrent problem is how to provide students with the tools and strategies they need to comprehend this difficult text within the challenges of the school curriculum.

\section{Special Needs of English Language Learners}

The growing population of English Language Learners continues to cause concern for the schools systems because of the historically documented achievement gap between native English speaking students and English language learners. This is a significant 
issue because statistics show this group of children is increasing rapidly in our school systems. English language learners in the United States now number over 5 million and represent approximately 10 percent of K-12 students (AACC, 2009).

The development of disciplinary literacy and English language proficiency are key elements in the academic success of English language learners (Carrier \& Tatum, 2006). Students' word knowledge plays a critical role in their academic success (Tompkins, 2009). Yet, many of these students are coming to school without the benefits of exposure to academic language, scientific academic language, vocabulary, and background knowledge needed to fully comprehend informational text because they do not have the advantage of parental input with academic language and scientific academic language in English. They are coming to school from different countries with different cultures to learn school subjects in a language different from their home language. When these students come to school they need to learn science in a second language and science as a second language (Roth, 2005).

Many English language learners are challenged in school by the academic discourse demands of textbooks, writing assignments, lectures, and formal class discussions. Not only are they hindered in their elementary, middle and high school years, they will need academic language proficiency to succeed in college and the workforce (Kinsella, 2005). How they learn academic English depends on many factors including their native language proficiency, school experiences, motivation, personality, family's literacy level, socioeconomic status and cultural isolation (Tompkins, 2009). For many students with limited exposure to the academic language used in school, vocabulary used in content areas is difficult to comprehend because the context in school 
is culturally unfamiliar, especially the comprehension of scientific academic language found in content area text. It is crucial for the academic and social success of these students who have limited access to English, especially academic English, to get sufficient instruction at school.

Zwier (2004) refers to academic English as the third language for English Language Learners, calling the social language heard in the hallways, community, and media the second language. This third language, Academic English, is more complex with figurative expressions, different grammar structures, and verb tenses. Surface level telling and meaning with word lists and definitions does not provide enough information for ELLs to thoroughly understand new words with a depth of meaning. English language learners need 5 to 7 years to become proficient in CALP and many English learners never reach proficiency (Tompkins, 2009). Learning academic English is essential for all students, but the challenge is even greater for English language learners.

Oral language proficiency is widely used at the state level to determine program placement and advancement for English language learning students. Yet the field of oral English development, especially academic oriented proficiency of ELLs, is neglected and requires more rigorous scientific research (Tong, Irby, Mathes, \& Kwok, 2008). Tong's 2008 study examined the effectiveness of a 2-year oral English intervention on English language learners. Results of the study showed that the combined components of the intervention made a difference in oral English-language proficiency between students in enhanced and control conditions at the early grade level.

Educators at a 2009 conference by the National Center for Research on the Educational Achievement and Teaching of English Language Learners emphasized the 
importance of teaching oral English (Zehr, 2009). Agreeing that oral language is good for all students, Harvard Professor Catherine Snow presented the idea that at-risk students are totally dependent on schools to give it (academic language) to them, while other students can get it in other places (Zehr, 2009). When students listen to spoken academic language, they can guess the meaning of unfamiliar words by paying attention to the speakers' purpose, intonation, and facial expressions (Zwier, 2004). It takes multiple encounters for students to create meanings and store them in memory. Students who have not had the benefits of listening to and practicing with academic language need increased practice with oral academic receptive (listening) and productive (speaking) language to experience better reading comprehension (Zwier, 2004).

There is a constant debate between educators and politicians about the most effective ways to evaluate the academic achievement of students in the United States. Under Title I of the Federal No Child Left Behind Act of 2001, schools are accountable for ensuring that English language learners master the same academic content in reading, mathematics, and science as non-English learning students. Title III of the Act holds states and districts accountable for ensuring that English language learners make progress and develop skills in listening, speaking, reading, writing, and comprehending English. The No Child Left Behind Act requires that school districts that receive Title III funds are monitored to see if they meet three Annual Measurable Achievement Objectives (AMAO) for their English language learners.

AMAO 1 measures progress in English language acquisition for individuals based on the Comprehensive English Language Learning Assessment (CELLA). AMAO 2 measures progress in the percentage of students who become proficient in English based 
on CELLA. AMAO 3 measures performance on the attainment of academic standards based on Florida Comprehensive Achievement Test (FCAT). Based on the Florida Department of Education statistics for the 2006-2007 and the 2007-2008 school years, the percent of Florida districts that met criteria for AMAO 1 and AMAO 2 rose. No Florida districts met all three objectives for these years. The 2008-2009 statistics show the percentage of applicable districts meeting criteria rose for the first and second objectives, yet only 8 districts, approximately 14\%, were able to meet the criteria for all three annual objectives. The percentages dropped slightly in $2009-2010$, with only $6 \%$ of the Districts meeting criteria for AMAO3, and only 7\% of Florida Districts met all Title III AMAOs. Miami Dade did not meet AMAO3, performance on the attainment of academic standards based on the FCAT, (http://www.fldoe.org.aala/amao.asp ). Even though the English Language Learners are making progress in English language acquisition and the percentage of students becoming proficient in English is rising, students are still lagging in the attainment of academic standards.

One crucial step in English Language Learners attaining the desirable academic standards could be attaining proficiency with the academic language used in the assessments (Wong, Filmore, \& Snow, 2002). Without the benefits of exposure of academic English and practice with the vocabulary, the students struggle to realize full comprehension.

\section{Using Informational Text}

Nonfiction text is any text that is factual. Informational text is a type of nonfiction that varies from other types of nonfiction in its purpose, features, and format (Duke \& Bennett-Armistead, 2003). The purpose of informational text is to convey 
information about the natural or social world. The features of informational text talk about whole classes of things, often in a timeless way. The format includes reference books, "all about" books, and process-informational books. Informational text exposes students to academic language and structure, builds background knowledge, and introduces vocabulary. Nonfiction informational text, often called expository text, is interesting and motivating with pictures and photographs of real word phenomena relevant to students' everyday lives.

In reference to the National Reading Panels (2000) recommendation that educators focus on decoding and phonetic skills, Neuman, 2010, criticizes the panel's narrow criteria for excluding important studies on background knowledge. She argues that children need to engage with new content, to think and grapple with new ideas. Her meta-analysis of studies about content understanding or comprehension examined 22 studies describing forty experiments on instructional strategies for science classes from third grade to the beginning of college. The results showed the most effective interventions focused on the structure and function of students' scientific knowledge base, proving the tremendous role background knowledge plays in reading comprehension.

One reason young students have difficulty with this type of text is the preference for story book reading and the lack of early exposure to expository text. Increasing exposure to informational text helps students build content knowledge necessary for connecting new learning with what they already know. In most elementary classrooms, story is the most predominant genre (Moss, 2004), and young children are typically read story books with fictional characters. In 2000, Nell Duke found that little informational 
text was available in first grade classrooms and that students spend on average only 3.6 minutes with informational text per day. This important research discovery has led to increased interest in exposing students to this genre at an earlier age.

In the last decade, there has been an increase in the availability of appealing informational text and studies involving elementary students' interaction with information text (Duke, \& Bennett-Armistead, 2003, Moss, 2004, Pappas, 2006, Donovan \& Smolkin, 2011). Still, there is much to be learned. Even though this type of reading is found in most of the standardized tests, until recently, there has been little emphasis on it in the primary grades. If students are assessed with this type of reading, why don't we begin to prepare them earlier, and what is the best way to accomplish this?

In a 10-year longitudinal study, first grade reading ability was reliably linked to exposure to print and individual differences in exposure to print were found to predict differences in the growth in reading comprehension ability throughout elementary school and beyond (Cunningham \& Stanovich, 1997). Therefore, by exposing young students to the genre of informational text at an earlier age and providing increased opportunities to orally practice with the language and structure of informational text, the students should experience positive effects on their academic language and reading comprehension ability.

Reading informational text requires different reading skills than storybook reading, which usually centers on characters, settings, problems, and solutions. Informational or expository text is often used to explain or persuade. Science text often uses three organizational patterns; cause and effect, generalization to details, or 
problem/solutions (Beers, 2003). The text has a different structure which requires attention to headings and captions, and awareness of comprehension strategies that focus on main idea and details, comparison, cause and effect, problems and solutions, and sequence.

In school, informational text often contains information about unknown topics and complex or abstract concepts. The new information and new vocabulary found in this text can make it harder for students to predict and make inferences (Fry, Kress, \& Fountoukidis, 2000). Since the characteristics and conventions of informational text are not so familiar to many students, it would make sense to emphasize reading strategies for this genre to young students. Yet, most primary instruction and most of the previous vocabulary studies with young children still concentrate on storybook reading.

Completing a study on non-fiction in early-grade classrooms, Duke (2003) proposed 3 beliefs that may explain the absence of informational text in primary classrooms. The beliefs that children cannot handle informational text and/or do not like informational text are unsupported with more evidence in favor of children's preference for informational text. Several studies have suggested that expository text is both appropriate for, and interesting, to young children (Donovan \& Smoklin, 2002, Pappas 2006, Mantzicopoulos \& Patrick, 2010). The third belief is that children should first learn to read and later read to learn around fourth grade. Duke's 2003 research indicates that including more informational text in first grade classrooms has positive effects on reading and writing achievement, as well as motivation. Providing students with exposure to informational text at an early age exposes them to the structure of academic vocabulary (Duke 2003). 
Moss, (1997) designed a study to measure first grade students' comprehension of expository text using retelling as an assessment. Informational text was read aloud to the students and after listening to the book, the students each drew a picture based on the book and retold the information. The students were able to summarize, identify important information, provide opinions and rationales for their opinions, and connect the text to their own lives. The findings indicated that the children were more capable of comprehending expository text than previously thought and suggested that earlier exposure to these books may develop greater facility in understanding expository text (Moss, 1997).

Another study analyzing young students' responses to science-related informational text also supported the view that children enjoyed informational text and that science related informational text is appropriate for children in the primary grades. This study suggested that the children were likely to benefit from science-related informational text with respect to both reading and science learning (Mantzicopoulos \& Patrick, 2010.) Science related informational text can facilitate the development of content knowledge and conceptual understanding, and also communicate processes of discipline-specific knowledge acquisition (Pappas, 2006). More emphasis should be placed on reading informational text at younger ages so students become familiar with the vocabulary and nonfiction text structures such as description, sequence, comparison and contrast, cause and effect, and problem and solutions.

With changing curriculum and assessments, students' needs are changing too. Students today are accessing more information and different kinds of information at an alarming rate. Many students need more than exposure, they need to be taught how to 
read expository text, with instruction that focuses on vocabulary and structure.

Textbooks are no longer the primary resources for information. Teachers and students use computers and other types of technology daily. Chalkboards are being replaced with Smartboards. Students do homework and reading online, and are involved with many different forms of text. Today's students need different reading skills to navigate online, and evaluate and analyze information from the Internet. Students are better able to comprehend and retain the information found in informational text when they learn to use the organization and structure (Goldman \& Rakestraw, 2000). Teachers are realizing that students need more familiarity with, and understanding of, expository text if they are to survive in the information age (Moss, 2004).

Pappas examined the role of the information book genre in integrated science literacy research and practice. Results from Pappas' 2006 investigation of information books and science literacy showed that typical informational children's books are the best resources for fostering children's scientific concepts as well as their appropriation of science discourse. Informational text is strategic here because this type of engagement in real world phenomena is hard to accomplish using only stories. Yet, her analysis revealed the use of, and research on, information books in science instruction to be quite limited in consideration of the fact that so many researchers call for approaches that connect science learning with language and literacy.

Informational books are excellent sources for new words. A group of researchers (Beck, et al., 2002) developed a program to determine benefits of Read Alouds with informational text. The goals were to enhance comprehension through interspersed open questions that forced students to consider the story ideas, discuss them and make 
connections, and develop vocabulary. Pappas' (2006) experiences with urban first and second grade students focused on hands-on explorations and discussions around them, read aloud sessions of informational books, and other writing and drawing activities. Analysis of classroom discourse showed that the narrative talk in the beginning of the unit changed and became more scientific at the end. She emphasizes that children cannot truly learn science unless they also learn the distinctive language of science and maintains that students cannot accomplish that goal using only story books or hybrid books. To successfully comprehend content area text, specifically science text in this study, students need to learn how to interact with the text.

\section{Multimodal Active Learning and Oral Engagement}

The goal of this study's intervention including multimodal active learning and oral engagement is to help equalize children's early experiences in the amount and type of talk needed to achieve academic language proficiency. Effective instructional practices for developing academic language include providing students multiple encounters with targeted words through collaborative active tasks where students write, speak, listen, and read (Flynt \& Brozo, 2008). Immersion in massive amounts of rich written and oral language can cause high rates of vocabulary growth (Nagy \& Scott, 2000). Multimodal, context-embedded learning activities, in the form of Academic Text Talk, provide opportunities for students to orally practice with new vocabulary and scientific academic language needed to succeed in school.

In many schools, there is more instructional focus on receptive vocabulary and knowledge than productive or expressive vocabulary and knowledge, indicated by more 
emphasis on reading and comprehension than talking and writing (Honig, 2010). There are several reasons for this. Many instructional strategies which involve talking and writing are more time consuming. Teachers are under pressure to cover prescribed curriculum and adhere to pacing guides. Testing or measuring expressive language is also more complex than receptive vocabulary. Typical multiple choice vocabulary tests do not always assess students' ability to actually use specialized language to communicate ideas. Also, teachers may not be familiar with strategies utilized to practice and assess oral and written academic language.

The way to help students become proficient in any language is to let them participate in using it for some authentic purpose. Students learn science talk when they participate in doing something that involves talking science (Gee, Kelly, Roth, \& Yerrick, 2005). Following are active learning strategies to help students learn how to talk science.

One method to help students, and especially English language learners, develop both academic language proficiency and content literacy is by expanding the concepts of word walls (Cunningham, 1995) to create sentence walls. Word walls are lists of words designed to foster students' sight and meaning vocabulary. Sentence walls are similar to word walls but they provide visual displays of well-formed phrases and sentences. The sentence templates may include examples for inquiry questions and statements. Sentence walls may help all students who need help constructing well-formed academic English sentences. English language learners will find them especially beneficial because sentence walls can provide a visual scaffold of language to help them become more familiar with the sentence structure found in informational text (Carrier\& Tatum, 2006). When students learning English are actively taught when and where to insert phrases 
from the sentence wall, they are more prepared to interact in discussions with other students who speak English.

Retelling is another strategy that can be used to help teach expository text structure and help internalize vocabulary. Retellings are oral or written postreading recalls during which children relate what they remember from reading or listing to a particular text (Moss, 2004). For many years, the common thinking was that young children were incapable of comprehending expository text, so most previous studies with elementary students focused on retelling as an oral summary of a narrative text. The structure of these retellings is usually based on story elements such as character/setting/problem/solution.

Moss (1997) assessed first grade students' ability to retell an informational trade book after hearing it read aloud using a 5-point scale that evaluated main ideas and supporting details, sequences, inferences beyond the text, relating text to own life, understanding of text organization, summary, and personal opinion with justification. Moss's Informational Retelling Scale is a rubric that provides a holistic evaluation and also assesses students' ability to relate information to their personal lives and infer beyond the text. The results suggested that young children are capable of comprehending expository text when it is presented orally. The students were able to summarize, identify important information, and give a rationale for their opinions. The results indicated that students do make personal connections similar to the ways they connect narrative text to their own experience. The research suggests that retelling shows potential as a means of assessing young children understanding of expository text, and that earlier exposure to expository text may facilitate comprehension (Moss, 1997). 
Students can use retellings to organize their ideas, discover main ideas and supporting details, and become more aware of their personal responses to reading, use of language, and their audience (Beers, 2003). When reading in content areas, students can use retellings to help them be more specific in their summarizing. Retelling differs from a summary in that students try to recall as much information as possible instead of just the main points. Moss (2004) stresses that teacher modeling is a critical first step in teaching students the process of retelling informational text. Many students need help recognizing structure in expository text but when retelling the information, they can sense text organization and identify relationships among pieces of information, and develop their oral language abilities (Moss, 2004). Moss feels this strategy may also be of greater value to ESOL students because the concrete nature of informational text can help them make connections between their first and second languages. Students can work in pairs to retell informational text to gain confidence in academic language.

A recent study examined the use of retelling as an assessment developed to document young children's narrative responses to science-related informational text (SciT). The SciT Narrative Production Assessment (NPA) was modeled after a preliterate assessment for meaning making and comprehension of fictional narrative picture books. The SciT combines materials and questioning strategies used in research on children's retelling after exposure to narrative and/or information books. The complexity of responses was coded as to thematic meanings, comments beyond the text's themes, including references to pictorial content, verbal output complexity, and the use of informational language (Mantzicopoulos \& Patrick, 2010). Evidence from this research supports the idea that children understand and enjoy science-related informational text 
and benefit in respect to both their reading and science learning. Accuracy of paraphrasing also suggests that opportunities for retelling and interaction during book reading facilitates children's thematic meaning making and the appropriation of new word meanings into children's vocabulary (Mantzicopoulos \& Patrick).

Multimodal activities, when children learn using all their senses, demonstrate that children learn best when they are actively engaged in their learning. Active engagement in learning is a characteristic of constructivist learning theory. To determine the effects of using multisensory vowel instruction during word study, Donnell (2007), conducted research with third graders. The intervention lessons followed a progression from children's oral language to phonological and phonemic awareness, to phonics, to specific vowel-spelling patterns. The multisensory features had auditory, visual, and kinesthetic components and were both receptive and productive. Data acquired from this study supported the effectiveness of the multisensory word-study program as a whole-class intervention (Donnell, 2007).

A study that explored students meaning making in creating multimodal informational books focused on the semiotic interplay between students' drawings and their text. The analysis revealed that after an integrated science unit with multiple exposure to informational texts, second and third graders were capable of expressing their ideas using appropriate scientific language and images, and used minor text features such as labels, captions, and dialogue bubbles (Pappas \& Varelas (2009). 


\section{Theory}

Constructivist theory is based on the theory that people construct their own knowledge and children learn by doing. Constructivism is the predominant underlying theory in science teaching and learning and highlights the child's active role in constructing knowledge from personal experience (Gibbons, 2008). It combines ideas from John Dewey, Lev Vygotsky, Jerome Bruner, and Jean Piaget. The concept of active learning is a fundamental principle in constructivism. John Dewey maintained that children learn from active engagement with their surroundings. Lev Vygotsky's (1934/1963) theory of intellectual development is based on the basic principle that the contents of our thinking and the habits of our lives originate in our social interactions with others.

Building on Vygotsky's theory, Jay Lemke studied the concept of becoming a village and learning together through social experience. In learning about social collaboration, Lemke (2002) states that although we may teach scientific and technical vocabulary, we rarely explicitly teach students how to talk science. Knowing that it is important to explicitly teach scientific vocabulary, providing students oral practice in using new vocabulary and academic structure could be an important step in improving students' scientific literacy.

Kelly (2005) examines the role of description in learning science. Following the socio-cultural theory, he states that "the cultural practices that count as science for a group are defined in and through social interaction, including, importantly, uses of language in particular ways for particular purposes" (p.99). This suggests that educators 
need to carefully consider the resources available for the children and how they are positioned to use those resources to the students' benefit to construct science through coordinated activities.

\section{Review of the Literature on the Instruments}

There are many ways to assess or measure vocabulary knowledge. Evaluations can measure receptive and productive vocabulary. Word meanings and definitions are often measured with standardized tests, teacher made tests, and informal tests. Teachers informally assess students' word knowledge throughout the day as they listen while students talk in class and examine their writing. Teachers also use standardized tests required by the state, and assessments published by textbook companies purchased by school districts. However, language examined through standardized measures alone may not reflect a child's improved performance in general spontaneous language (Jimenez, 2006). August and Shanahan (2008) report criticism of many of the commercial oral language proficiency tests because they do not assess students' actual use of the language to communicate in social or academic contexts. Aukerman (2007) believes it is destructive to view proficiency in decontextualized language (CALP) as a prerequisite for successful participation in school because language must be in context to be meaningful at all. Tompkins (2009) feels many vocabulary tests have limited use because they do not indicate whether students have ownership of a word or the ability to apply the vocabulary in meaningful and genuine ways. Tompkins proposes a variety of strategies to ask students to talk or write about what they are learning including reading logs, journals, oral reports, word maps, diagrams, biographies, poems, stories, letters, and projects to 
demonstrate actual use of newly learned words. Beck, McKeown, \& Kucan (2002) also emphasize the importance of multiple measures to assess vocabulary and comprehension.

Although we often think of retelling just as an instructional strategy, retellings can also be used as an assessment. Moss (2003) believes that using a rubric to provide a framework for teacher evaluation of student retellings is similar for using a rubric to evaluate writing samples. Using a rubric as a scoring method recognizes the students' response as a whole and assesses one's ability to identify main ideas, relevant details, and overall text structure. The rubric also reflects one's ability to infer beyond the text, summarize, and relate information from the text to the students' own life. The rubric used in this study was developed specifically for use with informational text (Fine, 2012).

This study used a combination of measures to assess students' vocabulary knowledge and comprehension in both receptive and expressive language. The teachers informally assess and reinforce language skills throughout the day in their interactions with the students. Rubrics were used to assess student participation in retelling and writing activities. Teachers used the standardized unit tests that accompany the chapters in the textbook published by Scott Foresman. The students were also assessed using a unit specific vocabulary text created by the National Energy Education Development (NEED) which adheres to National Science Standards. The Woodcock-Muñoz Language Survey-Revised (WMLS-R), a norm-referenced standardized test, was used as a pre and posttest measure to assess students' language proficiency.

WMLS-R was selected for this study because it is a collection of seven tests that provide a broad sampling of proficiency in oral language, language comprehension, 
reading, and writing. The WMLS-R emphasizes the role of cognitive-academic language proficiency (CALP) levels in assessment of comprehension. Scores from this normreferenced measure can be generated for 11 academic language clusters which include oral language, oral expression, language comprehension, applied language proficiency and oral language-total.

The WMLS-R is used to help users meet requirements under several major Federal education laws. The No Child Left Behind Act calls for annual assessment of English language proficiency in reading, writing, speaking and listening. Title III legislation requires reporting of student progress in English language comprehension. The WMLS-R is used for these purposes and is also used to meet requirements under IDEA (Individuals with Disabilities Education Act of 2004. IDEA requires that difficulties in English language proficiency be ruled out before referring students for special education for specific learning disabilities (SLD).

\section{Summary}

The ultimate goal in reading is comprehension. Vocabulary is an essential component of successful reading comprehension (NRP, 2000). The role of oral language is very important in the process of acquiring vocabulary. ELLs often struggle more because of insufficient background knowledge and limited exposure to academic language. Informational text offers purpose and relevance, is useful to build background knowledge, and provides exposure to vocabulary and structure of academic language. Introducing activities using informational text at an early age benefits all students, especially ELLs, by exposing them to scientific background knowledge, vocabulary, and 
practice with academic language. The effects of using Academic Text Talk on the development of diverse second graders' academic language proficiency and reading comprehension were investigated in this study. 


\section{CHAPTER 3}

\section{METHODS AND PROCEDURES}

This research study investigated the role that oral language plays in developing scientific academic language, and used a quasi-experimental, pre/posttest comparison design. The design was nonequivalent because the subjects were not randomly designated in groups. Academic Text Talk was used as an intervention to expose young children to informational text and provide opportunities for the students to orally practice using new vocabulary and academic language. The multimodal, context-embedded learning experiences were designed to scaffold verbalization of new words and ideas and lead to deeper comprehension. The text-centered instructional method refers to the common practice of reading the textbook pages, completing workbook pages, and taking the publisher developed assessments with little classroom activity and discussion.

In this chapter, the research questions and hypotheses are presented. The participants and sampling procedures are provided, and the research design is explained. This chapter also includes information on the instrumentation used to measure academic language proficiency and comprehension, and methods for data collection and analysis. The limitations of the study are examined, and a brief summary is included.

\section{Research Questions and Hypotheses}

The research questions and hypotheses for this study were developed to assess the

effects of Academic Text Talk on the comprehension of scientific academic language for diverse second graders. 


\section{Research Questions:}

1. Is there a difference in the scientific academic language proficiency between the students who are instructed using Academic Text Talk as compared to students who are instructed using a text-centered method?

2. Is there a difference in the scientific academic language proficiency by treatment (Academic Text Talk, text-centered) and sex for the students?

3. Is there a difference in the scientific academic language proficiency by treatment and English language status (English language learners, native English speakers) for the students?

\section{General Research Hypotheses:}

1. There is a relationship between the use of Academic Text Talk to increase students' oral practice with academic language and their oral academic language proficiency compared to the oral academic language proficiency of students taught using a text-centered method, as measured by mean scores on the Woodcock-Muñoz Language Survey-Revised (WMLS-R) when controlling for initial vocabulary knowledge.

2. There is a relationship between the use of Academic Text Talk to increase students' oral practice with academic language and their academic language proficiency and reading comprehension compared to the academic language proficiency and reading comprehension of students taught using a text-centered 
method, as measured by mean scores on the Woodcock-Muñoz Language SurveyRevised (WMLS-R) test when controlling for initial vocabulary knowledge.

\section{Specific Research Hypotheses:}

Hypothesis 1a: Students using Academic Text Talk will have greater improvement in their oral academic language proficiency and reading comprehension as measured by mean scores of the Woodcock Muñoz Language Survey-Revised when controlling for initial vocabulary knowledge on the Florida Assessments for Instruction in Reading (FAIR) test compared to those taught using a text-centered method.

Hypothesis 1b: Students using Academic Text Talk will have greater improvement in their oral academic language proficiency and reading comprehension as measured by mean scores on the unit specific vocabulary tests developed by the National Energy Education Development Project (NEED) when controlling for initial vocabulary knowledge on the Florida Assessments for Instruction in Reading (FAIR) test compared to those taught using a text-centered method.

Hypothesis 2a: Boys taught using Academic Text Talk will have greater improvement in their oral academic language proficiency and reading comprehension as measured by mean scores on the Woodcock Muñoz Language Survey-Revised when controlling for initial vocabulary knowledge on the Florida Assessment for Instruction in Reading (FAIR) test compared to girls.

Hypothesis 2b: Boys taught using Academic Text Talk will have greater improvement in their oral academic language proficiency and reading comprehension as measured by mean score on the unit specific vocabulary test developed by the 
National Energy Education Development project (NEED) when controlling for initial vocabulary knowledge on the Florida Assessment for Instruction in Reading (FAIR) test compared to girls.

Hypothesis 3a: English language learners taught using Academic Text Talk will have greater improvement in their oral academic language proficiency and reading comprehension as measured by mean scores on the Woodcock Muñoz Language Survey-Revised when controlling for initial vocabulary knowledge on the Florida Assessments for Instruction in Reading (FAIR) test than native English speakers, when controlling for initial vocabulary knowledge on the FAIR test.

Hypothesis 3b: English language learners taught using Academic Text Talk will have greater improvement in their oral academic language proficiency and reading comprehension as measured by mean scores on the unit specific vocabulary tests developed by the National Energy Education Development Project (NEED) when controlling for initial vocabulary knowledge on the Florida Assessments for Instruction in Reading (FAIR) test than native English speakers.

\section{Participants and Sampling Procedures}

\section{Sample}

Second grade students from a K-8 Center within a large public school district in southeast Florida were selected to participate in this study. Second grade was chosen because of their primary status and their ability to express their understandings orally and in writing. The students were all in the same school and the selection was nonprobabilistic because it was a convenience sampling. The students were in 6 classrooms. 
Three classes received the Academic Text Talk treatment and three classes were taught with a text-centered method. The students were not randomly selected as the students were pre-assigned to classes.

In the sample school, the school district uses the Comprehensive English Language Learning Assessment (CELLA) as a measure of English Language Learners' growth in mastering skills in English. One class in each grade level has students who are identified as ESOL (English for Speakers of Other Languages) Levels 1 and 2 and the other classes have a mixture of native English speaking students and students identified as ESOL Levels 3, 4, and 5 (exit level). Although the majority of students speak another language at home, only the ones who were currently in the ESOL (English for Speakers of Other Languages) Program were identified for purposes of this study. Race and sex were defined using the school district's demographic records. Students in both the comparison and the Academic Text Talk classes included girls and boys, and native English speakers and English language learners of Levels 3, 4, and 5. The diversity of the students in each classroom presents a need for all students to have sufficient practice with academic vocabulary. Student scores from the initial Florida Assessments in Instruction and Reading (FAIR) tests given at the beginning of the school year were used to assess ability similarities in vocabulary and in reading comprehension in all groups. 


\section{Variables}

\section{Independent Variables}

For Research Question 1, the two levels of the instructional treatment are Academic Text Talk and the text-centered method of instruction. Academic Text Talk refers to the participation in multimodal, context-embedded learning experiences focused on informational text and designed to scaffold verbalization of new words and ideas with the intention of accelerating the development of diverse students' academic language proficiency. The text-centered method refers to the common practice of reading the textbook pages, and completing the workbook pages and publisher assessment with little activity and discussion.

Sex is the additional independent variable for the second research question. Boys and girls were compared within both instructional treatment groups.

English Language Status (English language learners/ Native English Speakers) is the additional independent variable used in the third research question to compare student achievement in both instructional groups. English language learners are defined by student scores on the Comprehensive English Language Learning Assessment (CELLA) which the state of Florida currently uses to assess English language proficiency in our schools.

\section{Dependent Variables}

The level of academic language proficiency was measured with two tests: The Woodcock-Muñoz Language Survey-Revised (WMLS-R) pre and post, and unit specific 
vocabulary tests developed by the National Energy Education Development Project (NEED).

\section{Research Design}

The design for the study was selected to determine how increasing young students' oral practice with academic language, giving them more time to talk about informational text, would affect their academic language proficiency. Because of the fact that not all variables were able to be controlled due to the school setting, a quasiexperimental comparative design was chosen. The design is a nonequivalent design because the students are not totally randomly designated in groups. However, it is the goal of the school administration to make the classes as similar as possible in regards to percentages of ethnic groups, sex, and academic ability within each second grade class.

The students participated in pre group written tests and individual oral language tests as components of the Woodcock-Muñoz Language Survey-Revised assessment. They also participated in textbook unit specific scientific academic vocabulary tests throughout the treatment. The treatment group received the "Academic Text Talk" and the comparison group received text-centered instruction using the textbook, workbook, and textbook published assessments, without Academic Text Talk. Students in the Academic Text Talk group had more classroom activities designed to scaffold their oral use of academic language.

Academic Text Talk, the combination of multimodal learning experiences focused on increasing oral practice with academic language, was implemented over an 8 week period. The School district's curriculum currently requires students to have 180 minutes 
of instruction in science, including one hands-on lab activity, each week. This averages approximately 35 minutes each day of instruction, but daily schedules within classrooms vary slightly because of the school-wide schedules. Second grade class schedules in the sample school currently include three 1-hour instructional periods per week. The treatment group received the same amount of instructional time as the comparison group weekly, but activities within the scheduled time allowed for more active learning including retelling, use of sentence frames, discussion and oral engagement with academic language.

The researcher provided lesson plans for 8 weeks for both groups of students. The topics were selected from the school district's Curriculum and Instruction pacing guide and followed the Next Generation Sunshine State Standards. The plans, found in Appendix A, include vocabulary words and 12 lessons on the topic of Energy and 12 lessons on the topic of Forces and Motion. The basic lesson plans were designed using the school adopted textbook and workbook pages, as well as the publisher designed assessments. The Academic Text Talk plans include the supplemental activities designed for more active learning and practice with academic vocabulary. These activities include increased exposure to other types of informational text and outside resources to stimulate increased oral practice with academic language.

After the Academic Text Talk treatment was implemented for the 8 weeks, the students in both groups participated in the WMLS-R group posttest and individual oral language tests, as well as unit-specific scientific academic vocabulary test developed by the National Energy Education Development Project. 


\section{Choice of Words for Instruction}

Beck, McKeown, and Kucan (2002) categorized words into three tiers. The first tier consists of the most basic words that rarely require instructional attention to their meanings in school. The second tier includes words that are of high frequency for mature language users and are found across a variety of domains. The third tier contains words that are often limited to specific domains and are used with low frequency. Their research shows instruction of words in the second tier to be most productive. When they select tier two words they think about whether students would be able to express the concepts represented by the words with vocabulary they already have. Then, learning the new vocabulary would allow the students to describe with greater specificity people and situations with which they are already familiar.

Vocabulary words for this study were selected using the criteria for tier two words. They were selected because of their importance and utility across a variety of domains. The words have instructional potential because they can be worked with in a variety of ways to build rich representations and have useful connections to other words

and concepts. They also have the ability to provide precision and specificity in conceptual understanding. The vocabulary words for this study were selected from the student text book, published by Scott Foresman, and materials from the National Energy Education Development Project. Many of the specific words chosen are science process words such as observe, measure, infer, predict, and evaluate selected because of their utility across domains. Other vocabulary words such as solar, thermal, fuel, force, and friction were selected for their importance to the concepts in the unit. See Appendix A for a complete list of vocabulary included in the study. 


\section{Instrumentation}

The Woodcock-Muñoz Language Survey-Revised (WMLS-R) was selected for this study because it consists of a collection of seven tests that provide a broad sampling of proficiency in oral language, language comprehension, reading, and writing. The WMLS-R emphasizes the role of cognitive-academic language proficiency (CALP) levels in assessment of comprehension. The construct of CALP includes words such as analyze, contrast, therefore, or examine that are usually learned in academic settings and are not typically used in everyday conversations. CALP also involves knowledge and literary skills involving conceptual-linguistic knowledge that occurs in the context of semantics, abstractions, and context-reduced linguistic forms, as demonstrated in the ability to reason with words (Francis, Alvarado, \& Wendling, 2010). Scores from this norm-referenced measure can be generated for 11 "academic language" clusters which include oral language, oral expression, language comprehension, applied language proficiency and oral language- total. A table showing the subtests and academic language clusters can be found in Appendix B.

The WMLS-R is used to help users meet requirements under several major Federal education laws. The No Child Left Behind Act calls for annual assessment of English language proficiency in reading, writing, speaking and listening. Title III legislation requires reporting of student progress in English language comprehension. The WMLS-R is also used to meet requirements under the Individuals with Disabilities Education Act of 2004 (IDEA) which requires that difficulties in English language proficiency be ruled out before referring students for special education for specific learning disabilities (SLD). 
A review in the Seventeenth Mental Measurements Yearbook (Brown, 2007) reported that adequate descriptive and reliability statistics were given for each of the seven tests and separately for the 11 academic language clusters. The statistics are broken down by age groups ranging from ages 2 to $80+$. The manual gives all possible intercorrelations of the separate tests and academic clusters (Alvarado, Ruef, \& Schrank, 2005). The median (across age groups) adjusted split-half reliability for the seven tests ranged from 0.76 to 0.97 , which is above the minimum acceptable reliability score for group predictions of 0.65 (Newman \& Newman, 2011). Using Mosier's procedures for weighted composites, the median (across age groups) reliabilities for the 11 academic language clusters ranged from 0.88 to 0.98 . Newman and Newman (2011) suggest the general rule for individual predictions is that the reliability estimate should be 0.8 or higher.

Information was provided in the test manual regarding the content, concurrent, and construct validity of the test. The different tests in the WMLS-R were selected to provide an assessment of students' language proficiency based on tasks involving listening, speaking, reading, writing, and comprehension. The manual provides a table which summarizes the content coverage and task requirements for each of the tests at all levels of difficulty. The clusters, which combine results from two or more tests to provide a broader measure of ability, improve the content validity of measures for broad abilities such as oral language and reading-writing because they minimize the danger of making important decisions based on a single aspect of behavior (Alvarado, et al. 2005).

Evidence of concurrent, or known group validity, was provided by administering different test batteries to special samples of the different age groups. The sample of 
school age children were administered the WMLS-R tests and the Wechsler Intelligence Scale for Children-Third Edition (WISC-III). The high correlations between the WMLS$\mathrm{R}$ tests and clusters and the WISC-III Verbal IQ and Verbal Comprehension Index shows evidence that the WMLS-R measures the construct of CALP.

Criterion-related validity was examined separately through four different studies of different age groups; preschool, school-age students, university students, and bilingual students (Mental Measurements Yearbook, 2005). Various criterion measures included verbal, nonverbal, mathematics, total achievement, and IQ tests. Descriptive statistics provided with correlation coefficients between the WMLS-R scores and the academic cluster scores using the various criterion measures indicate the WMLS-R scores are moderately correlated with other verbal measures.

\section{Data Collection}

The initial phase of the study consisted of teacher training, acquiring parental permission, and pre-testing the students. The teachers first participated in a survey at the beginning of the study to determine which strategies they were currently using. This Teacher Instructional Strategy Survey is presented in Appendix C. The researcher trained the teachers in the administration of the subtests of Woodcock Muñoz Language Survey-Revised using the information and sample items in the comprehensive manual. The teachers in the Academic Text Talk treatment group were also trained in the strategies and use of materials for the supplemental activities. All the teachers completed the Fidelity checklists, found in Appendix D, to ensure compliance with the lesson plans. 
The researcher also observed classrooms weekly to assess adherence to the plans and address any questions and concerns the teachers had.

Students' scores from the beginning of the year FAIR test were used to compare vocabulary and reading ability, and assess similarity in groups. The students were then pretested to assess their oral language proficiency as measured by the WMLS-R and prevocabulary NEEDS tests that were specific to the units of study.

In the second phase, the students participated in content area lessons identified to meet the objectives in the Miami-Dade Public Schools Curriculum and Instruction Pacing Guide for the 2011-2012 school year. Miami Dade Public Schools currently uses the Next Generation Sunshine State Standards to drive their instruction. The students had end of unit topic specific vocabulary tests, and textbook chapter tests. They also participated in the WMLS-R as a posttest to assess changes in comprehension and language proficiency.

The students were also assessed using the resources provided by the text book publishers. Students participated in completing workbook pages in class and summary lessons for home learning. The teachers used the textbook chapter assessments to evaluate mastery of the chapter objectives.

\section{Data Analysis}

The research questions for this study were developed to assess the effect of Academic Text Talk on the comprehension of scientific academic language for diverse second graders. Frequencies and percentages were calculated for sex and English language status by treatment group. Means and standard deviations were calculated for 
the WMLS-R pre and posttest, the NEED tests and the FAIR vocabulary test by treatment group.

To answer the first research question that there is a difference in the scientific academic language proficiency for the diverse students who were taught using Academic Text Talk as compared to students who were taught using a text-centered method, analysis of covariance (ANCOVA) was performed on the pre to post WMLS-R increase by treatment group with initial vocabulary (FAIR) score as a covariate. The NEEDS tests were analyzed similarly.

To answer the second research question, which examined the sex difference in the scientific academic language proficiency for diverse students who were taught using Academic Text Talk compared with those who were taught using a text-centered method, analysis of covariance (ANCOVA) was performed on the pre to post WMLS-R increase by treatment group and sex with initial vocabulary (FAIR) as a covariate. The NEEDS tests were analyzed similarly.

To answer the third research question to determine if there was a difference in the scientific academic language proficiency between English language learners and native English speakers who were taught using Academic Text Talk as compared with those who were taught using a text-centered method, analysis of covariance (ANCOVA) was performed on the pre to post WMLS-R increase by treatment group and English language status with initial vocabulary (FAIR) as a covariate. The NEEDs tests were analyzed similarly. Chi squared tests were used to assess relationships between sex and treatment 
group, and English language status and treatment group. IBM SPSS v21 (Chicago, 2012) was used for all data analysis and the level of significance for all tests was $p<.05$.

\section{Limitations}

Limitations of this study included a small sample size and lack of information regarding students' prior knowledge or interest in the topics of the study. The selection of students was non-probabilistic because it was convenience sampling. The students were not totally randomly selected as the students were pre assigned to classes and only students who returned consent forms and participated in all pre and post tests were included in the study. Results should be generalized with caution to schools who share similar characteristics including demographics and instructional resources. Another limitation of the study was that the length of time the treatment was implemented was restricted because of school schedules. A more extensive period of time could have different results.

\section{Summary}

A quasi experimental pre/posttest comparative design was selected for this study because the goal of the research was to determine the effectiveness of increasing exposure to informational text and oral practice with academic language on the development of diverse students' academic language proficiency. A non-probabilistic convenience sample of second grade students was selected to receive or not receive additional treatment during their normal science instructional period. The weakness of this non-probabilistic sampling can be lessened by replication of the research study and subsequent sampling (Newman and Newman, 2011). The researcher hypothesized 
relationships between students' exposure to informational text and academic language, oral practice with academic language, and students' academic language proficiency. 


\section{CHAPTER 4}

\section{RESULTS}

This research study to determine the effects of using Academic Text Talk as an intervention to accelerate the academic language development of diverse second graders was successfully implemented at a K-8 Center within a large public school district in southeast Florida. A total of 91 students participated in both the pre and post Woodcock Muñoz Language Survey-Revised assessments, vocabulary tests developed by the National Energy Education Development Project, and had FAIR scores from the initial testing period. Thirty-eight (41.8\%) were boys and fifty-three (58.2 \%) were girls. Eighteen (19.8\%) of the students were ESOL (English Speakers of Other Languages) Levels 3, 4, and 5, as assessed by the Comprehensive English Language Learners Assessment (CELLA) currently used by Miami-Dade Public School District to identity English Language Learners. The frequencies by sex and English language learning status for the Academic Text Talk (ATT) Treatment group and the comparison group taught using a text-centered method are displayed in Table 1. There were no significant differences between groups for sex, $p=.707$, or English language learners, $p=.638$.

The Woodcock Muñoz Language Survey-Revised was selected for this study because it emphasizes the role of cognitive-academic language proficiency (CALP) levels in assessment of comprehension. The NEEDS vocabulary tests assessed unit specific vocabulary selected for its importance to the concepts of the units, as well as scientific process words which were selected because of their utility across domains. Both instruments were used to answer the following research questions developed to assess the 
effects of Academic Text Talk on the comprehension of scientific academic language for diverse second graders.

1. Is there a difference in the scientific academic language proficiency between the students who were taught using Academic Text Talk as compared to students who were taught using a text-centered method?

2. Is there a difference in the scientific academic language proficiency by treatment (Academic Text Talk, text-centered) and sex for the students?

3. Is there a difference in the scientific academic language proficiency by treatment and English Language status (English language learners, native English speakers) for the students?

The analysis of collected data was achieved in IBM SPSS and included ANCOVAs as discussed in Chapter 3. Student scores from the initial Florida Assessments in Instruction and Reading (FAIR) were used to assess ability similarities in vocabulary and reading comprehension in all groups. 
Table 1

Frequencies of Sex and English Language Learners Status by Group

\begin{tabular}{lccccc}
\hline & \multicolumn{2}{c}{ Academic Text Talk $(n=50)$} & & \multicolumn{2}{c}{ Comparison $(n=41)$} \\
\cline { 2 - 2 } \cline { 5 - 6 } Variable & Frequency & Percentage & & Frequency & Percentage \\
\hline Sex & 20 & 40.0 & & 18 & 43.9 \\
Boys & 30 & 60.0 & & 23 & 56.1 \\
Girls & 9 & & & & \\
English Language Learners & & & & & \\
Yes & 41 & 82.0 & & 32 & 78.0 \\
No & & & & & \\
\hline
\end{tabular}

This study analyzed the WMLS-R W scale (Growth Scale), an equal-interval scale that is well suited for measuring growth or change over time (Alvarado, Ruef, \& Schrank, 2005).

Table 2 shows the pre mean scores on the FAIR, the WMLS-R Oral LanguageTotal Cluster and the Language Comprehension Cluster, and the two NEEDS Vocabulary Tests for both groups. The mean for the FAIR vocabulary test for the ATT treatment group was significantly higher than the mean for the comparison group, $p<.001$. The ATT treatment group also had a higher mean for the WMLS-R Comprehension W score, $p=.016$, and a higher mean in the second NEEDS vocabulary test, $p=.009$. 
Table 2

Pre Means on the FAIR, WMLS-R Oral W, WMLS-R Comprehension W, NEEDS

Vocabulary Definition and Symbols Tests by Group

\begin{tabular}{|c|c|c|c|c|}
\hline \multirow[b]{2}{*}{ Variable } & \multicolumn{2}{|c|}{$\begin{array}{l}\text { Academic Text Talk } \\
(n=50)\end{array}$} & \multicolumn{2}{|c|}{$\begin{array}{l}\text { Comparison } \\
(n=41)\end{array}$} \\
\hline & Mean & SD & Mean & SD \\
\hline FAIR Vocabulary $* *$ & 60.46 & 23.42 & 44.90 & 15.95 \\
\hline \multicolumn{5}{|l|}{ WMLS-R } \\
\hline Oral W & 492.96 & 6.74 & 490.54 & 6.24 \\
\hline Comprehension $\mathrm{W}^{*}$ & 494.84 & 6.78 & 491.10 & 7.85 \\
\hline \multicolumn{5}{|l|}{ NEEDS } \\
\hline Definitions & 27.71 & 20.55 & 22.25 & 16.87 \\
\hline Symbols** & 33.54 & 13.76 & 26.00 & 12.36 \\
\hline
\end{tabular}

\section{Research Question One}

The first research question proposed by this study was: Is there a difference in the scientific academic language proficiency between the students who use Academic Text Talk as compared to students who use text-centered methods?

Hypothesis 1a: Students using Academic Text Talk will have greater improvement in their oral academic language proficiency and reading comprehension as measured by mean scores of the Woodcock Muñoz Language Survey-Revised when controlling for initial vocabulary knowledge on the Florida Assessments for Instruction in Reading (FAIR) test compared to those taught using a text-centered method. Table 3 presents the 
mean increases from pre to post on the WMLS-R Oral and Comprehension W scores by group adjusted for FAIR vocabulary assessment. There were significant differences in the WMLS-R Oral Cluster W scores between groups, $p=.024$. The adjusted mean Oral W increase of students in the Academic Text Talk group (adj $M=6.68$ ) was almost double that of the comparison group (adj $M=3.94)$. There were no significant differences between groups in the WMLS-R Comprehension W Scores.

\section{Table 3}

Mean Increases from Pre to Post on WMLS-R Oral W and WMLS-R Comprehension W by Group Adjusted for FAIR Vocabulary Assessment

\begin{tabular}{|c|c|c|c|c|c|}
\hline \multirow[b]{2}{*}{ WMLS-R Variable } & \multicolumn{2}{|c|}{$\begin{array}{l}\text { Academic Text Talk } \\
(n=50)\end{array}$} & \multicolumn{2}{|l|}{$\begin{array}{l}\text { Comparison } \\
(n=41)\end{array}$} & \multirow[b]{2}{*}{$p$-value } \\
\hline & Adj Mean & $\mathrm{SE}$ & Adj Mean & $\mathrm{SE}$ & \\
\hline Oral W & 6.63 & 0.75 & 3.94 & 0.84 & $.024 *$ \\
\hline Comprehension W & 7.68 & 0.94 & 6.68 & 1.05 & .493 \\
\hline
\end{tabular}

Note: WMLS-R Woodcock Muñoz Language Survey-Revised, W = growth scale, ${ }^{*} p<$ .05 .

Hypothesis 1b: Students using Academic Text Talk will have greater improvement in their oral academic language proficiency and reading comprehension as measured by mean scores on the unit specific vocabulary tests developed by the National Energy Education Development Project (NEED) when controlling for initial vocabulary knowledge on the Florida Assessments for Instruction in Reading (FAIR) test compared to those taught using a text-centered method. Table 4 presents the results of the pre and post NEEDS vocabulary tests. 
Students in the Academic Text Talk group showed significantly higher means increases from pre to post tests on the NEEDS vocabulary tests than the group taught using a text-centered method, (Table 4 ), $p$ s $<.001$. Because the NEEDS vocabulary tests contained unit specific vocabulary, the students in the Academic Text Talk had more opportunity to orally practice with the exact vocabulary words. Students in the ATT group produced even greater increases in the second vocabulary test which included symbols for different types of energy. The ATT treatment group had much greater adjusted mean increase for the NEEDS vocabulary test than the comparison group. The researcher attributes this greater increase to the combined activities that included chants with hand motions that the students learned for each type of energy. 


\section{Table 4}

Mean Increases from Pre to Post on NEEDS Definitions and NEEDS Symbols by Group Adjusted for FAIR Vocabulary Assessment

\begin{tabular}{|c|c|c|c|c|c|}
\hline \multirow[b]{2}{*}{ NEEDS Variable } & \multicolumn{2}{|c|}{$\begin{array}{l}\text { Academic Text Talk } \\
(n=48)\end{array}$} & \multicolumn{2}{|l|}{$\begin{array}{l}\text { Comparison } \\
(n=40)\end{array}$} & \multirow[b]{2}{*}{$p$-value } \\
\hline & Adj Mean & SE & Adj Mean & $\mathrm{SE}$ & \\
\hline Definitions & 29.44 & 3.82 & 6.42 & 4.21 & $<.001 * *$ \\
\hline Symbols & 36.34 & 3.29 & 6.65 & 3.63 & $<.001 * *$ \\
\hline
\end{tabular}

Note: NEEDS $=$ National Energy Education Development Project, $* * p<.01$

\section{Research Question Two}

Is there a difference in the scientific academic language proficiency by treatment (Academic Text Talk, text-centered) and sex for the students?

Hypothesis 2a: Boys taught using Academic Text Talk will have greater improvement in their oral academic language proficiency and reading comprehension as measured by mean scores on the Woodcock Muñoz Language Survey-Revised when controlling for initial vocabulary knowledge on the Florida Assessment for Instruction in Reading (FAIR) test compared to girls.

To answer this second research question, data from pre and posttests from both the WMLS-R and NEEDS tests were analyzed by group and by sex. Table 5 presents the mean increases from pre to post scores on WMLS Oral W and WMLS-R Comprehension W by group and sex adjusted for FAIR vocabulary assessment. The researcher anticipated that boys would present greater increases in their mean scores because of literature supporting their need for active involvement in learning. The Academic Text 
Talk boys showed higher increases than the girls in the $\mathrm{W}$ score, but these differences were similar to those between girls and boys in the comparison group, $p \mathrm{~s}>.05$. Thus, the Academic Text Talk treatment did not favor the boys on either the WMLS-R Oral W or WMLS-R Comprehension W scores.

\section{Table 5}

Mean Increases from Pre to Post on WMLS-R Oral W and WMLS-R Comprehension W by Group and Sex Adjusted for FAIR Vocabulary Assessment

\begin{tabular}{|c|c|c|c|c|c|}
\hline \multirow[b]{2}{*}{ WMLS-R Variable } & \multicolumn{2}{|c|}{$\begin{array}{l}\text { Academic Text } \\
\text { Talk }(n=50)\end{array}$} & \multicolumn{2}{|c|}{$\begin{array}{l}\text { Comparison } \\
(n=41)\end{array}$} & \multirow[b]{2}{*}{$\begin{array}{c}\text { Interaction } \\
p \text {-value }\end{array}$} \\
\hline & Adj Mean & $\mathrm{SE}$ & Adj Mean & $\mathrm{SE}$ & \\
\hline Oral W & & & & & .881 \\
\hline Boys & 7.36 & 1.18 & 4.43 & 1.24 & \\
\hline Girls & 6.15 & 0.97 & 3.55 & 1.12 & \\
\hline Comprehension W & & & & & .327 \\
\hline Boys & 7.93 & 1.46 & 8.39 & 1.53 & \\
\hline Girls & 7.55 & 1.20 & 5.29 & 1.38 & \\
\hline
\end{tabular}

Note. WMLS-R = Woodcock Muñoz Language Survey-Revised, $\mathrm{W}=$ Growth scale, $n($ Treatment, Boys $)=20, n$ (Treatment, Girls $)=30, n($ Comparison, Boys $)=18, n$ $($ Comparison, Girls) $=23$.

Hypotheses 2b: Boys taught using Academic Text Talk will have greater improvement in their oral academic language proficiency and reading comprehension as measured by mean score on the unit specific vocabulary test developed by the National Energy Education Development project (NEED) when controlling for initial vocabulary knowledge on the Florida Assessment for Instruction in Reading (FAIR) test compared to 
girls. Table 6 presents the mean increases for the NEEDS vocabulary tests. There were no significant differences on either NEEDS test between boys and girls by group, $p \mathrm{~s}>$ .05. Girls in the Academic Text Talk group had somewhat higher mean increases than boys in the ATT group, but this pattern was similar for the comparison group.

\section{Table 6}

Mean Increases from Pre to Post on NEEDS Definitions and Symbols by Group and Sex Adjusted for FAIR Vocabulary Assessment

\begin{tabular}{|c|c|c|c|c|c|}
\hline & $\begin{array}{l}\text { Academic T } \\
(n=50)\end{array}$ & xt Talk & $\begin{array}{l}\text { Comparison } \\
(n=41)\end{array}$ & & \\
\hline Variable & Adj Mean & $\mathrm{SE}$ & Adj Mean & $\mathrm{SE}$ & $\begin{array}{c}\text { Interaction } \\
p \text {-value }\end{array}$ \\
\hline NEEDS Definitions & & & & & .524 \\
\hline Boys & 25.27 & 5.84 & 6.40 & 6.15 & \\
\hline Girls & 32.43 & 4.97 & 6.42 & 5.67 & \\
\hline NEEDS Symbols & & & & & .690 \\
\hline Boys & 31.86 & 5.01 & 4.58 & 5.27 & \\
\hline Girls & 39.50 & 4.26 & 8.38 & 4.86 & \\
\hline
\end{tabular}

\section{Research Question Three}

Is there a difference in the scientific academic language proficiency by treatment and English language status (English language learners, native English speakers) for the students? 
Hypothesis 3a: English language learners taught using Academic Text Talk will have greater improvement in their oral academic language proficiency and reading comprehension as measured by mean scores on the Woodcock Muñoz Language SurveyRevised when controlling for initial vocabulary knowledge on the Florida Assessments for Instruction in Reading (FAIR) test than native English speakers.

English language learners were identified as Levels 3, 4, and 5 on the Comprehensive English Language Learning Assessment (CELLA) which the school uses as a measure of English language learner's growth in mastering skills in English. Although the majority of students speak another language at home, only the ones who were currently in the ESOL (English for Speakers of Other Languages) Program were identified for purposes of this study. Eighteen students were identified as ESOL, nine in the ATT treatment group, and nine in the Comparison Group, so there was no significant difference in distribution across groups.

Table 7 presents the mean increases from pre to post for the WMLS-R Oral Language-Total Cluster and the Comprehension Cluster W scores. There were no significant differences on the WMLS-R scores between ELLs and native speakers by group, $p \mathrm{~s}>.05$. The English language learners in both the ATT treatment and comparison groups had smaller increases on most of the WMLS-R scores than the native English speakers. 


\section{Table 7}

Mean Increases from Pre to Post on WMLS-R Oral W and WMLS-R Comprehension W by Group and English Language Learner Status Adjusted for FAIR Vocabulary Assessment.

\begin{tabular}{|c|c|c|c|c|c|}
\hline \multirow[b]{2}{*}{ WMLS-R Variable } & \multicolumn{2}{|c|}{$\begin{array}{l}\text { Academic Text Talk } \\
\qquad(n=50)\end{array}$} & \multicolumn{2}{|c|}{$\begin{array}{l}\text { Comparison } \\
(n=41)\end{array}$} & \multirow[b]{2}{*}{$\begin{array}{c}\text { Interaction } \\
p \text {-value }\end{array}$} \\
\hline & Adj Mean & $\mathrm{SE}$ & Adj Mean & $\mathrm{SE}$ & \\
\hline Oral W & & & & & .918 \\
\hline No & 7.13 & 0.87 & 4.37 & 0.93 & \\
\hline Yes & 4.90 & 1.76 & 1.85 & 1.78 & \\
\hline Comprehension W & & & & & .366 \\
\hline No & 8.18 & 1.10 & 6.42 & 1.17 & \\
\hline Yes & 5.83 & 2.21 & 7.22 & 2.24 & \\
\hline
\end{tabular}

Note. WMLS-R = Woodcock Muñoz Language Survey-Revised. No = Native English Speaker, Yes $=$ English Language Learner, $n$ (Treatment, Yes $)=9, n($ Treatment, No) $=$ $41, n$ (Comparison, Yes) $=9, n$ (Comparison, No) $=32$.

Hypothesis 3b: English language learners taught using Academic Text Talk will have greater improvement in their oral academic language proficiency and reading comprehension as measured by mean scores on the unit specific vocabulary tests developed by the National Energy Education Development Project (NEEDS) when controlling for initial vocabulary knowledge on the Florida Assessments for Instruction in Reading (FAIR) test than native English speakers. 
There were no significant differences in the NEEDS increases between ELL and native speakers by group, $p \mathrm{~s}>.05$. However, the interaction effect of ELL status by group for NEEDS definition approached significance, $p=.092$, (Table 8).

The English Language Learners in the ATT group improved somewhat more $(M=$ 47.76) than the native speakers $(M=24.16)$ on the NEEDS definition, while in the Comparison group, both ELL $(M=7.99)$ and native speakers' $(M=7.30)$ improvements were similar.

\section{Table 8}

Mean Increases from Pre to Post on NEEDS Definitions and Symbols by Group and English Language Learners Status Adjusted for FAIR Vocabulary Assessment.

\begin{tabular}{|c|c|c|c|c|c|}
\hline & \multicolumn{2}{|c|}{$\begin{array}{l}\text { Academic Text } \\
\text { Talk } \\
(n=50)\end{array}$} & \multicolumn{2}{|c|}{$\begin{array}{l}\text { Comparison } \\
(n=41)\end{array}$} & \\
\hline Variable & Adj Mean & $\mathrm{SE}$ & Adj Mean & $\mathrm{SE}$ & $\begin{array}{c}\text { Interaction } \\
p \text {-value }\end{array}$ \\
\hline NEEDS Definitions & & & & & .092 \\
\hline No & 24.16 & 4.36 & 7.30 & 4.60 & \\
\hline Yes & 47.76 & 8.58 & 7.99 & 8.67 & \\
\hline NEEDS Symbols & & & & & .982 \\
\hline No & 36.54 & 3.88 & 6.84 & 4.10 & \\
\hline Yes & 35.70 & 7.63 & 5.73 & 7.72 & \\
\hline
\end{tabular}

Note. NEEDS = National Energy Education Development Project. No = Native English Speaker, Yes $=$ English Language Learner. $n($ Treatment, Yes $)=9, n($ Treatment, No $)=$ $41, n$ (Comparison, Yes) $=9, n$ (Comparison, No) $=32$. 


\section{Summary}

Students taught using the Academic Text Talk multimodal strategies showed significantly greater increases in their pre to posttest means of the Woodcock Muñoz Language Survey Revised and the National Energy Education Development Project Vocabulary tests than students taught using the text-centered method. Students in the ATT group showed significantly greater increases in the WMLS-R Oral Language Total scores of the assessments than the comparison group; however, there were not significant differences by group on the WMLS-R Comprehension increases. Students in the ATT group also showed significantly greater increases on both the Definitions and Symbol specific vocabulary tests developed by the National Energy Education Project (NEEDS) than the students taught using the text-centered method. Thus, hypothesis one was supported. However, as hypothesized by the researcher in the second research question, boys did not show significantly greater increases than girls. The English language learners did not show significantly greater increases than native English speakers as hypothesized for the third research question. The interaction effect of ELL status by group for NEEDS definition approached significance, $p=.092$. The English language learners in the ATT group improved somewhat more compared to the native speakers than in the Comparison group, where both ELL and native speakers' improvements were similar. 


\section{CHAPTER 5}

\section{SUMMARY, CONCLUSIONS, and IMPLICATIONS}

Many students, especially young English language learners, have difficulty comprehending content area text because their prior experience offered limited exposure to academic language and the structure of informational text. A well-developed vocabulary and knowledge about the topic of a text is critical for comprehension, yet without sufficient background knowledge and practice with academic language, students struggle to learn new vocabulary and fully comprehend. Oral language is important to the development of reading vocabulary and active engagement with learning new words is important for effective vocabulary learning. This study investigated the relationship between multimodal context-embedded learning experiences designed to increase diverse second graders' oral practice with academic language on their acquisition of scientific academic language and reading comprehension.

The problem is that many students lack opportunities for active engagement with the type of vocabulary needed to succeed in school. If their home experience has not provided a substantial foundation in vocabulary and academic English, along with exposure to informational text, they will continue to have difficulty comprehending the cognitive language used in school.

The purpose of the study was to determine the effectiveness of using a researcher developed combination of multimodal strategies, referred to as Academic Text Talk, designed to increase opportunities for students to actively practice with the academic language found in content area text. Exposing young students to the language and 
structure of informational text and providing opportunities for student discourse about their reading can help students verbalize their thinking and develop academic vocabulary necessary to have confidence in discussing their ideas.

\section{Statement of the Procedures}

Students from six second grade classrooms $(n=91)$ from a K-8 Center within a large public school district in southeast Florida participated in the study. Three classes were taught using Academic Text Talk, a researcher developed combination of strategies designed to increase active oral practice with academic language, and three classes were taught with the text-centered method of using textbook, workbook, and publisher developed assessments. Both classes had the same instructional time, but the students in the Academic Text Talk treatment group had more time devoted to active oral practice with academic language.

The timeline for the research study spanned 12 weeks. The first 2 weeks included securing permission for student participation, teacher training for administering the assessment instruments and implementing the Academic Text Talk activities, and pretesting. The students were pretested using the Woodcock Muñoz Language SurveyRevised and 2 unit specific vocabulary tests developed by the National Energy Education Development Project (NEEDS). The students participated in 8 weeks of science instruction including a 4 week unit on Energy, and a 4 week unit on Forces and Motion. After completing the instructional period, the students participated in post testing using the same instruments. The Florida Assessments in Instruction in Reading (FAIR) test was used as a covariate to assess similarities and abilities of the students. 


\section{Research Questions and Specific Research Hypothesis}

\section{Research Questions}

Is there a difference in the scientific academic language proficiency for the students who use Academic Text Talk as compared to students who use a text-centered method?

Is there a difference in the scientific academic language proficiency by treatment (Academic Text Talk, text-centered) and sex for the students?

Is there a difference in the scientific academic language proficiency by treatment and English Language status (English language Learners, native English speakers) for the students?

\section{Specific Research Hypothesis}

Hypothesis 1a: Students using Academic Text Talk will have greater improvement in their oral academic language proficiency and reading comprehension as measured by mean scores of the Woodcock Muñoz Language Survey-Revised when controlling for initial vocabulary knowledge on the Florida Assessments for Instruction in Reading (FAIR) test compared to those taught using a text-centered method. This hypothesis was supported as there were significant differences between groups in the WMLS-R Oral Cluster W scores. The students using ATT had greater mean increase in the Oral Clusters than the comparison group, but not in the Comprehension clusters.

Hypothesis 1b: Students using Academic Text Talk will have greater improvement in their oral academic language proficiency and reading comprehension as measured by mean scores on the unit specific vocabulary tests developed by the National 
Energy Education Development Project (NEED) when controlling for initial vocabulary knowledge on the Florida Assessments for Instruction in Reading (FAIR) test compared to those taught using a text-centered method. Hypothesis $1 \mathrm{~b}$ was also supported as students in the Academic Text Talk group showed significantly higher means increases from pre to post tests on both the NEEDS vocabulary tests. As the NEEDS vocabulary tests contained unit specific vocabulary, the students in the Academic Text Talk had more opportunity to orally practice with the exact vocabulary words. The ATT Treatment group had much greater adjusted mean increases for both NEEDS vocabulary tests than the comparison group, especially for the second test, which included symbols for the different types of energy. The researcher attributes this greater increase to the combined activities that included chants with hand motions the student learned for each type of energy.

Hypothesis 2a: Boys taught using Academic Text Talk will have greater improvement in their oral academic language proficiency and reading comprehension as measured by mean scores on the Woodcock Muñoz Language Survey-Revised when controlling for initial vocabulary knowledge on the Florida Assessment for Instruction in Reading (FAIR) test compared to girls. This hypothesis was not supported. Although the Academic Text Talk boys showed higher increases than the girls in both the $\mathrm{W}$ scores of the WMLS-R, these differences were similar to those between girls and boys in the comparison group.

Hypothesis 2b: Boys taught using Academic Text Talk will have greater improvement in their oral academic language proficiency and reading comprehension as measured by mean score on the unit specific vocabulary test developed by the National 
Energy Education Development project (NEED) when controlling for initial vocabulary knowledge on the Florida Assessment for Instruction in Reading (FAIR) test compared to girls. This hypothesis was not supported. Girls in the Academic Text Talk group had somewhat higher mean increases than boys in the ATT group, but this pattern was similar for the students in the comparison group.

Hypothesis 3a: English Language Learners taught using Academic Text Talk will have greater improvement in their oral academic language proficiency and reading comprehension as measured by mean scores on the Woodcock Muñoz Language SurveyRevised when controlling for initial vocabulary knowledge on the Florida Assessments for Instruction in Reading (FAIR) test than native English speakers. Hypothesis 3a was not supported. There were no significant differences on the WMLS-R scores between ELL and native speakers by group. The English language learners in both the ATT Treatment and comparison groups had smaller increases on the WMLS-R scores than the native English speakers and those increases were similar.

Hypothesis 3b: English Language Learners taught using Academic Text Talk will have greater improvement in their oral academic language proficiency and reading comprehension as measured by mean scores on the unit specific vocabulary tests developed by the National Energy Education Development Project (NEEDS) when controlling for initial vocabulary knowledge on the Florida Assessments for Instruction in Reading (FAIR) test than native English speakers.

Hypothesis $3 b$ was not supported. There were no significant differences in the NEEDS increases between ELL and native speakers by group. However, the interaction 
effect of ELL status by group for NEEDS definition approached significance, $p=.092$. The English language learners in the ATT group improved somewhat more compared to the native speakers for the NEEDS definitions, while in the comparison group, both ELL and native speakers' improvements were similar.

\section{Conclusions}

Students taught using the Academic Text Talk multimodal strategies showed significantly greater increases in their pre to posttest means on the Woodcock Muñoz Language Survey-Revised Oral Language Totals and the National Energy Education Development Project Vocabulary tests than students taught using the text-centered method, $p \mathrm{~s}<.05$. Boys did not show significantly greater increases than girls, nor did English language learners show significantly greater increases than the native English speakers.

\section{Implications}

There was a positive relationship between the use of Academic Text Talk activities and the oral academic language proficiency for the students that participated in the multimodal activities. This supports the constructivist theory that children learn by doing. Results of this study supports the existing literature that states that students learn new vocabulary best when they have multiple opportunities in a range of settings to be actively involved in using new words to express understandings. Teachers can successfully scaffold children's learning with guidance and encouragement by facilitating more opportunities for the students to interact with academic text. 
This study adds to the research that is needed to understand how young children learn from informational text with Academic Text Talk. This combination of strategies is an essential step in developing academic vocabulary and recognizing deeper comprehension of content area text. The research results are beneficial to educators wanting to improve scientific academic language proficiency and comprehension.

\section{Discussion}

Academic language is becoming more prevalent in education, especially with the emphasis on new standards, informational text, and high stakes testing. The problem is that many students lack opportunities for active engagement with the type of vocabulary needed to succeed in school. The diversity of the students in today's classrooms makes the problem even more urgent because so many students have not had the benefit of oral practice with academic language, so they have more difficulty reading, comprehending, and using academic language in school. Teachers are hindered by time constraints, curriculum pacing guides, large classes, and discipline issues. However, if students were able be exposed to the structure and vocabulary of informational text at a younger age, and be able to actively practice using academic vocabulary across disciplines, the results of this type of intervention could benefit students in their long term academic careers.

Constructivist learning theory is based on the concept of children constructing meaning through active learning. Following Vygotsky's socio-cultural theory of cognitive development, the Zone of Proximal Development refers to the difference between what a child can achieve independently and what a child can achieve with guidance and encouragement from a skilled partner. Teachers can scaffold student 
learning by providing opportunities for students to gain experience with the language they need for academic success. The purpose of this study was to enhance young diverse students' academic language proficiency by increasing exposure to the language and structure of informational text, and increasing opportunities for them to be actively involved with the text by participating in multimodal activities designed to stimulate oral discourse.

What was revealed in this study was that the emphasis on scientific academic language, especially the science process words, made students more aware of their thinking processes. When the students started to distinguish between ideas such as infer, predict, compare/contrast, and started noticing text features and the organization of informational text, they became more actively involved in analyzing complex text. They were more able to break down the structure and find the information they needed, and they were able to use more precise terms to explain their thinking. For the students, identifying the name or label of a thinking process made it more intentional and they were eager to show that they could discriminate one thinking process from another.

Anecdotal records from the teachers shared that talking about the text and practicing using new vocabulary helped the students "think about their thinking" and made them more excited to "talk like scientists." Being able to practice using new vocabulary in a safe environment and to use the language for an authentic purpose seemed to be critical for student success.

The teachers remarked that they appreciated having the plans, resources, and materials readily available. They agreed that the students enjoyed the activities, and said 
they would like to know more ways to incorporate oral discourse in an independent yet structured way, that was also practical to incorporate into the already packed daily routine. Teachers need to be provided training in facilitating oral engagement with academic language, and they also need to have feasible teacher-student ratios and the time to provide these opportunities to help students develop their oral academic language proficiency.

Overall results indicated that the Academic Text Talk activities did enhance oral academic language proficiency, but did not present greater increases for boys over girls, or English language learners over native English speakers as hypothesized. This could be due to limitations such as the short intervention period, but it also shows that a more participatory instructional approach in which active involvement is part of the science classroom is beneficial to all students.

\section{Recommendations for Future Research}

This study took place over a period of 12 weeks utilizing the WMLS-R instrument and the NEEDS vocabulary tests. Based on the researcher's experiences in this study, it would be recommended to conduct a similar study over a longer period of time. Due to the public school schedule established at the district level, the instructional portion of the study had to be conducted during an 8 week period. Throughout this time frame, various school holidays and recess periods occurred which interrupted classroom instructional time. It is not known if this interruption had an effect on the learning experiences of the students. Utilizing the strategies across all subject areas throughout the day and 
conducting the study over a longer period of time could offer an opportunity for students to develop stronger language proficiency.

Further research is suggested to analyze long term scores in standardized science assessments. The school district currently assesses students using state mandated standardized science tests in the fifth and eighth grades. The long term analysis of the science scores for the second grade students involved in this study on the state's standardized science tests given in 3 year spans may show long term effects of the Academic Text Talk treatment. 


\section{REFERENCES}

Alvarado, C. G., Ruef, M. L., \& Schrank, F. A. (2005). Comprehensive Manual. Woodcock Muñoz Language Survey-Revised. Rolling Meadows, IL: Riverside Publishing.

Anderson, R., Wilson, P., \& Fielding, L. (1988). Growth in reading and how children spend their time outside of school. Reading Research Quarterly, 23(3). 285-303.

Assessment and Accountability Comprehensive Center, AACC. (2009). Framework for high-quality English language proficiency standards and assessments. San Francisco, CA: West Ed.

August, D., \& Shanahan, T. (2008). Developing reading and writing in second-language learners: Lessons from the report of the national literacy panel on languageminority children and youth. New York, NY: Routledge.

Aukerman, M. (2007). A culpable CALP: Rethinking the conversational/academic language proficiency distinction in early literacy instruction. The Reading Teacher, 626-635.

Beck, I., \& McKeown, M. (2001). Text talk: capturing the benefits of read-aloud experiences for young children. The Reading Teacher, 55(1), 10-20.

Beck, I., McKeown, M., \& Kucan, L. (2002). Bringing words to life: Robust vocabulary instruction. New York, NY: Guilford Press.

Beers, K. (2003). When kids can’t read: What teachers can do. Heinemann, Portsmouth, $\mathrm{NH}$.

Blachowicz, C.L., \& Fisher, P. (2000). Vocabulary instruction. In M.L. Kamil, P.B. Mosenthal, P.D. Pearson, \& R. Barr (Eds.), Handbook of reading research (Vol. 3, pp. 269-284). Mahwah, NJ: Earlbaum.

Brown, J.D. (2007). Review of Woodcock-Muñoz Language Survey-Revised. In K.F. Geisinger, R.A. Spies, J.F. Carlson, and B.S. Plake (Eds.), The seventeenth mental measurements yearbook. Lincoln, NE: Buros Institute of Mental Measurements. Retrieved from the Buros Institute's Test Review Online website: http://www.buros.org/

Burn, A. (2011). Children, media, \& the playground: Children's games in the new media playground. EnglishDramaMedia, 43-50.

Carrier, K., \& Tatum, A. (2006). Creating sentence walls to help English-language learners develop content literacy. The Reading Teacher 60(3), 285-288. 
Costa, A., \& Marzano, R. (1987). Teaching the language of thinking, Educational Leadership 45(2). 29-33.

Crowley, K., Callahan, M., Jipson, J., Galco, J., Topping, K., \& Shrager, J. (2000). Shared scientific thinking in everyday parent-child activity. Science Education 85(6). 712-732.

Cummings, J. (2008). BICS and CALP. Empirical and theoretical status of the distinction. In Street, B. \& Hornberger, H.H. (Eds.). Encyclopedia of Language and Education, $2^{\text {nd }}$ Edition, Volume 2: Literacy. (71-83). New York: Springer Science \& Business Media LLC.

Cunningham, P. (2000). Phonics they use: Words for reading and writing. New York, NY: Harper Collins.

Cunningham, A. \& Stanovich, K. (1998). What reading does for the mind. American Educator 22(1 \& 2), 8-17.

Cunningham, A. E., \& Stanovich, K.E. (1997). Early reading acquisition and its relation to reading experience and ability 10 years later. Developmental Psychology, 33(6). 934-5.

Donnell, W. J. (2007)). The effects of multisensory vowel instruction during word study for third-grade students. Reading Research Quarterly, 42(4). 468-471.

Donnelly, W., \& Roe, C. (2010). Using sentence frames to develop academic vocabulary for English Learners. The Reading Teacher, 64(2). 131-136.

Donovan, C. \& Smolkin, L. (2011). Supporting informational writing in the elementary grades. The Reading Teacher, 64(6). 406-416.

Duke, N., Bennett-Armistead, S., \& Roberts, E. (2003). Filling the great void: Why we should bring nonfiction into the early-grade classroom. American Educator. Retrieved from http://www.aft.org/pubs-reports/american_educator/spring2003/void.html.

Duke, N. K. \& Bennett-Armistead, V.S. (2003). Reading \& writing informational text in the primary grades: Research-based practices. New York, NY: Scholastic.

Dutro, S. \& Helman, L. (2009). Explicit language instruction: A key to constructing meaning, In L. Helman (Ed.). Literacy development with English learners: Research-based instruction in grades K-6 (pp. 40-63). New York, NY: Guilford Press. 
Fine, J. C. \& Mosser, P.K. (2011). Celebrating what children comprehend: Using a rubric for written retellings of narrative text. American Reading Forum Annual Yearbook [Online], Vol.31.

Flynt, E., Bozo, W. (2008). Developing academic language: Got words? The Reading Teacher 61(6). 500-502.

Fry, E., Kress, J., \& Fountoukidis, D. (2000). The reading teacher's book of lists $\left(4^{\text {th }}\right.$ ed.). San Francisco, CA: Jossey-Bass.

Gee. J. P. (2005). Language in the science classroom: Academic social languages as the heart of school-based literacy. In Yerrick, R. \& Roth, W. (Eds.). Establishing scientific classroom discourse communities: Multiple voices of teaching and learning research. 19-37. NJ: Erlbaum.

Gibbons, B. (2008)). Elementary preservice teachers' utilization of English language development instructional strategies in the teaching of science to English learners. Multicultural Education 15(3). 50-53.

Goldman, S.R., \& Rakestraw, J. S. (2000). Structural aspects of constructing meaning from text. In M. Kamil, P.B. Mosenthal, P.D. Pearson, \& R. Barr (Eds.), Handbook of reading research (Vol. 3, pp. 311-336). Mahwah, NJ: Erlbaum.

Hart, B., \& Risley, T. (1995) Meaningful Differences in the Everyday Experience of Young American Children. Baltimore Md.: Paul H. Brookes Publishing Co.

Hart, B., \& Risely, T.R. (2003). The early catastrophe: The 30 million word gap by age 3. American Educator. Retrieved from: www.aft.org/pubsreports/american_educator/spring2003/catastrophe.htm

Heisey, N., \& Kucan, L. (2010). Introducing science concepts to primary students through read- alouds: Interactions and multiple texts make the difference. The Reading Teacher, 63(8).666-676.

Honig, S. (2010). A framework for supporting scientific language in primary grades. The Reading Teacher, 64(1). 23-32.

Kelly, Gregory, (2005). Discourse, description, and science education. In Yerrick, R. \& Roth, W. (Eds.). Establishing scientific classroom discourse communities: Multiple voices of teaching and learning research (pp. 19-37). Mahwah, NJ: Erlbaum.

Kinsella, K. (2005, October). Preparing for effective vocabulary instruction. Aiming high [Aspirando a lo major] resource, 1-8. Retrieved January 29, 2011 from www.scoe.org/docs/ah/AH_kinsella1.pdf 
Lemke, J. (2002). Becoming the village: Education across lives. Learning for life in the $21^{\text {st }}$ Century. Ed. By G. Wells and G. Claxton: Blackwell.

Mantzicopoulos, P. \& Patrick, H (2010). "The seesaw is a machine that goes up and down": Young children's narrative responses to science-related informational text. Early Education \& Development, 21(3). 412-444.

Marzano, R. (1998). What are the general skills of thinking and reasoning and how do you teach them? The Clearing House 71(5). Ethnic News Watch.

Mcleod, S.A. (2007). Simply Psychology: Retrieved 28 January 2012, from http://www.simplypsychology.org/vygotsky.html.

Moss, B. (1997). A qualitative assessment of first graders' retelling of expository text. Reading Research and Instruction 37, 1-13.

Moss, B. (2004). Teaching expository text structures through information trade book retellings. The Reading Teacher 57(8). 710-718.

Nagy, W. \& Anderson, R. (1984). How many words are there in printed school English? Reading Research Quarterly, 19(3). 304-330.

Nagy, W. (2003). Teaching vocabulary to improve reading comprehension. ERIC Clearinghouse on Reading and Communication Skills. National Council of Teachers of English \& International Reading Association.

Nagy, W. \& Scott, J. (2000). Vocabulary processes. In M.L. Kamil, P.B. Mosenthal, P.D. Pearson, \& R. Barr (Eds.), Handbook of Reading Research 3, 269-284. Mahwah, NJ: Erlbaum.

National Institute of Child Health and Human Development. (2000). Report of the National Reading Panel. Teaching children to read: An evidence-based assessment of the scientific research literature of reading and its implications for reading instruction (NIH publication No. 00-4754). Washington, D.C.: U.S. Government Printing Office.

Neuman, S.B., \& Celano, D. (2001) Access to print in low-income and middle-income communities: An ecological study of four neighborhoods. Reading Research Quarterly. 36, 8-26.

Neuman, Susan B. (2010). Sparks fade, knowledge stays: The National early literacy panel's report lacks staying power. American Educator 34(3). 14-17.

Newman, I, \& Newman, C. (2011). Increasing the likelihood of publishing quantitative manuscripts. In T. Rocco \& T. Hatcher, (Eds.), The Handbook of Scholarly Writing and Publishing. 179-190. San Francisco: Jossey Bass. 
Newcombe, N. (2010). Picture this: Increasing math and science learning by improving spatial thinking. American Educator 34(2). 29-35.

Padak, N, \& Rasinski, T. (2009). The games children play. The Reading Teacher 62(4).

Pappas, C. (2006). The information book genre: Its role in integrated science literacy research and practice. Reading Research Quarterly 42(2). 226-250.

Pappas, C., Varela, M., Gill, S., Ortiz, I., \& Keblawe-Shamah, N. (2009). Multimodal books in science-literacy units: Language and visual images for meaning making. Language Arts, 86(3), 201-211.

Roberts, J., Jurgens, J., Burchinal, M. (2005). The role of home literacy practices in preschool children's language and emergent literacy skills. Journal of Speech, Language and Hearing Research 48(2). 345-359.

Roth, F., Speece, D, \& Cooper, D. (2002). A longitudinal analysis of the connection between oral language and early reading. The Journal of Educational Research 95(5).259-72.

Shymansky, J., Hand, B., \& Yore, L. (2000). Empowering families in hands-on science programs. School Science and Mathematics 100(21), 48-56.

Schrank, F.A., Alvarado, C.G., \& Wendling, B.J. (2010). Interpretive Supplement: Instructional interventions for English language learners related to the WoodcockMuñoz Language Survey-Revised Normative Update. Rolling Meadows, IL: Riverside Publishing.

Tompkins, G. E. (2009. Language arts: Patterns of practice $\left(7^{\text {th }}\right.$ ed.). Upper Saddle River, NJ: Pearson.

Tong, F., Lara-Alecio, R., Irby, B., Mathes, P. \& Kwok, O. (2008). Accelerating early academic oral English development in transitional bilingual and structured English immersion programs. American Educational Research Journal 45(4). 1011-1033.

Vygotsky, L.S. (1978). Mind in society: The development of higher psychological processes. Cambridge, MA: Harvard University Press.

Wasik, B.A., Bond, M.A., \& Hindman, A. (2006). The effects of a language and literacy intervention on Head Start children and teachers. Journal of Educational Psychology, 98 (1). 63-74.

Wong Fillmore, L., \& Snow, C.E. (2002). What teachers need to know about language. 
In C.T. Adger, C.E. Snow, \& D. Christian (Eds.), What teachers need to know about language. (pp. 7-54). Washington, DC: Center for Applied Linguistics.

Adger, C.E. Snow, \& D. Christian (Eds.). What teachers need to know about language. (pp. 7-54). Washington, DC: Center for Applied Linguistics.

Yopp, R.H., \& Yopp H. K. (2004). Preview-predict-confirm: Thinking aloud about the language and content of informational text. The Reading Teacher, 58(1), 79-83.

Zehr, M.A., (2009). Oral language skills for English-learners focus of researchers. Education Week 29(8). 8.

Zwiers, J. (2005). The third language of academic English. Educational Leadership 62(4). 60-63. 


\section{Appendices}
A. Lesson Plans for 2 Science Units: Energy, Forces and Motion including Academic Text Talk Activities for Science Units: Energy, Forces and Motion
B. Woodcock Muñoz Language Survey-Revised Cluster Chart
C. Teacher Instruction Strategy Survey
D. Teacher Instruction Fidelity Checklist 


\section{Appendix A}

\section{Science Unit Plans for Both Academic Text Talk \& Comparison Groups Energy, Forces and Changes in Motion \& How Magnets Work}

\begin{tabular}{|l|l|l|l|}
\hline $\begin{array}{l}\text { Initial } 2 \text { week period } \\
\text { pend home \& collect } \\
\text { permission slips }\end{array}$ & $\begin{array}{l}\text { Teacher Training for } \\
\text { WMLS-R, }\end{array}$ & $\begin{array}{l}\text { Teacher Training for } \\
\text { Academic Text Talk } \\
\text { Strategies }\end{array}$ & $\begin{array}{l}\text { Assemble materials, } \\
\text { supplies, copies for } \\
\text { lessons }\end{array}$ \\
Collect FAIR data & Begin Pretesting & Pretesting & Pretesting \\
\hline
\end{tabular}

\section{First Month, 12 Lessons on Energy - Both Treatment and Comparison Groups}

Each teacher received a booklet with the plans for a unit on Energy, and a unit on Forces and Motion. Both groups had the same topics, textbook pages, and essential questions. The detailed plans included objectives, correlations to standards, activities, materials needed, and evaluation procedures. For purposes of this document, the abbreviated lesson plans for both the Academic Text Talk treatment group and the comparison group using the text-centered method are displayed next to each other for easier comparison. However, for the study, teachers in each group only received the plans for their students. Teachers in the comparison group did not have access to the activities that the Academic Text Talk group used.

The Academic Text Talk treatment group received the same amount of instructional time as the comparison group, but the plans included supplemental activities designed for more active learning and oral practice with academic vocabulary within the scheduled time. Academic Text Talk activities include increased exposure to other types of information text, and activities such as retelling, use of sentence frames, discussion, songs, games, and chants designed to stimulate active, oral discourse with academic language. 


\begin{tabular}{|c|c|c|c|}
\hline $\begin{array}{l}\text { Week 1, Day 1: Directed } \\
\text { Inquiry - Which color } \\
\text { heats faster? } \\
\text { Intro \& 9.1, 268-273, } \\
\text { Teacher wraps } \\
\text { thermometers, } \\
\text { measures temperature. } \\
\text { Students observe and } \\
\text { infer. } \\
\text { vocab: energy, solar } \\
\text { energy } \\
\text { Evaluation (E.): } \\
\text { Workbook 104-104A }\end{array}$ & $\begin{array}{l}\text { Week 1, Day 2: How do } \\
\text { living things use } \\
\text { energy? } \\
9.2,274-277 \\
\text { Students read text. } \\
\text { Topic: Plants, animals \& } \\
\text { people get energy from } \\
\text { the sun. } \\
\text { food chains, food } \\
\text { groups: Wkbk 105-105A }\end{array}$ & $\begin{array}{l}\text { Week 1, Day 3: Using } \\
\text { and Saving Energy. } \\
\text { Read Info text Using \& } \\
\text { Saving Energy or leveled } \\
\text { readers. Discuss } \\
\text { Renewable, } \\
\text { nonrenewable, reduce, } \\
\text { reuse, repair, recycle. } \\
\text { E. Copy definitions in } \\
\text { notebook }\end{array}$ & $\begin{array}{l}\text { Materials for the Week: } \\
\text { Student text book \& } \\
\text { workbook, } \\
\text { thermometer } \\
\text { paper } \\
\text { student workbook } \\
\text { Trade book Using \& } \\
\text { Saving Energy or } \\
\text { Leveled readers }\end{array}$ \\
\hline $\begin{array}{l}\text { Academic Text Talk } \\
\text { (ATT) } \\
1.1 \text { Which color heats } \\
\text { faster? } \\
\text { Students actively work } \\
\text { in pairs or groups to } \\
\text { measure \& record data. } \\
\text { Orally report results to } \\
\text { class. }\end{array}$ & $\begin{array}{l}\text { ATT } \\
\text { 1.2 How do living things } \\
\text { use energy? } \\
\text { Students create paper } \\
\text { strip food chains by } \\
\text { writing a member of } \\
\text { food chain on } 1 \text { side \& } \\
\text { how it gets food on } \\
\text { other. Present to } \\
\text { partner \& orally explain } \\
\text { connections. }\end{array}$ & $\begin{array}{l}\text { ATT } \\
\text { 1.3 Using and Saving } \\
\text { Energy. } \\
\text { Teacher models } \\
\text { appropriate retelling, } \\
\text { explains criteria and } \\
\text { rubric. } \\
\text { Students actively work } \\
\text { in pairs to read and } \\
\text { retell to partner. }\end{array}$ & $\begin{array}{l}\text { ATT Materials: } \\
\text { Thermometers } \\
\text { Recording sheets } \\
\text { Song sheet } \\
\text { Paper strips, glue, \& } \\
\text { markers } \\
\text { Retelling rubric }\end{array}$ \\
\hline $\begin{array}{l}\text { Week 2, Day 1: Sources } \\
\text { of Heat. How Heat } \\
\text { Moves. } \\
9.3 \text {, Class reads p.278- } \\
281 \\
\text { Students copy } \\
\text { definitions for source, } \\
\text { fuel, conductor, friction } \\
\text { E: Wkbk 106-106A }\end{array}$ & $\begin{array}{l}\text { Week 2, Day 2: Where } \\
\text { does energy come } \\
\text { from? } \\
\text { Trade book: Where } \\
\text { Does Energy Come } \\
\text { From? List and discuss } \\
\text { different sources of } \\
\text { energy } \\
\text { E: Oral response } 3 \text { Q. } \\
\text { end of book }\end{array}$ & $\begin{array}{l}\text { Week 2, Day 3: Lab } \\
\text { Activity- What gives off } \\
\text { heat? } \\
\text { 9.4, 282-285. Lab: Place } \\
\text { thermometers in } \\
\text { different locations to } \\
\text { determine sources of } \\
\text { heat. } \\
\text { E: Wkbk 107-107A }\end{array}$ & $\begin{array}{l}\text { Materials: } \\
\text { Where Does Energy } \\
\text { Come From? } \\
\text { Class set of } \\
\text { thermometers } \\
\text { Flashlight, mirror, } \\
\text { prism (opt.) } \\
\text { (reflect, shadow) }\end{array}$ \\
\hline
\end{tabular}




\begin{tabular}{|c|c|c|c|}
\hline $\begin{array}{l}\text { ATT } \\
2.1 \text { Sources of heat. } \\
\text { How heat moves. } \\
\text { Students use sentence } \\
\text { frames to actively } \\
\text { practice structure and } \\
\text { vocabulary of academic } \\
\text { language. Examples } \\
\text { included in appendix. }\end{array}$ & $\begin{array}{l}\text { ATT } \\
2.2 \text { Where does energy } \\
\text { come from? } \\
\text { Read trade book Where } \\
\text { Does Energy Come } \\
\text { From? Students take } \\
\text { turns reading to } \\
\text { partner and retelling. } \\
\text { They work in pairs to } \\
\text { use rubric and self- } \\
\text { assess. }\end{array}$ & $\begin{array}{l}\text { ATT } \\
2.3 \text { Lab: What gives off } \\
\text { heat? } \\
\text { Students place ice } \\
\text { cubes in plastic cups on } \\
\text { different colored } \\
\text { papers in the sun. } \\
\text { Predict which will melt } \\
\text { first. Record data at } 5 \\
\text { minute intervals. Feel, } \\
\text { compare light } \& \text { dark } \\
\text { shirts while outside. }\end{array}$ & $\begin{array}{l}\text { ATT Materials } \\
\text { Sentence frames } \\
\text { written on board or } \\
\text { sentence strips } \\
\text { Where Does Energy } \\
\text { Come From? booklets } \\
\text { Ice, plastic cups, } \\
\text { construction paper, } \\
\text { recording sheets }\end{array}$ \\
\hline $\begin{array}{l}\text { Week 3, Day 1: What } \\
\text { are other kinds of } \\
\text { energy? } \\
\text { 9.5, 286-289. Motion, } \\
\text { wind, sound } \\
\text { Using electricity safely. }\end{array}$ & $\begin{array}{l}\text { Week 3, Day 2: How } \\
\text { sun drives the water } \\
\text { cycle. } \\
\text { Introduce vocabulary, } \\
\text { copy definitions for } \\
\text { Water cycle, } \\
\text { evaporated, condensed, } \\
\text { turbine, electricity } \\
\text { Read aloud Tales of } \\
\text { Annie Soakley or show } \\
\text { poster of water cycle. } \\
\text { E: Draw water cycle on } \\
\text { paper. }\end{array}$ & $\begin{array}{l}\text { Week 3, Day 3: Lab } \\
\text { Activity- How can you } \\
\text { change light? } \\
9.5 \text { extension, 290-291. } \\
\text { Observe, infer } \\
\text { Light bends in the } \\
\text { water, ROYGBIV } \\
\text { E: Activity Bk 97-98, Act. } \\
\text { Rubric }\end{array}$ & $\begin{array}{l}\text { Materials: } \\
\text { Tales of Annie Soakley } \\
\text { and/or } \\
\text { poster of the water } \\
\text { cycle } \\
\text { Copies of Activity Book } \\
\text { 97-98 } \\
\text { Activity Rubric }\end{array}$ \\
\hline $\begin{array}{l}\text { ATT } \\
3.1 \text { What are other } \\
\text { kinds of energy? } \\
\text { Students work in pairs } \\
\text { to read and retell The } \\
\text { Tale of Johnny Energy } \\
\text { Seed. Use rubric to } \\
\text { assess. }\end{array}$ & $\begin{array}{l}\text { ATT } \\
\text { 3.2 How sun drives the } \\
\text { water cycle. } \\
\text { Students work in pairs } \\
\text { to read and retell The } \\
\text { Tale of Annie Soakley. } \\
\text { Use rubric to self-assess } \\
\text { or evaluate partner. } \\
\text { Students create } \\
\text { spinning water cycles } \\
\text { w/paper plates and } \\
\text { fasteners. }\end{array}$ & $\begin{array}{l}\text { ATT } \\
\text { 3.3 How can you change } \\
\text { light? } \\
\text { Students use prism } \\
\text { glasses outside to } \\
\text { separate colors in the } \\
\text { light. Explain that you } \\
\text { need the sun behind } \\
\text { you to see a rainbow. } \\
\text { ROYGBIV. }\end{array}$ & $\begin{array}{l}\text { ATT Materials } \\
\text { Copies of The Tale of } \\
\text { Johnny Energy Seed and } \\
\text { The Tale of Annie } \\
\text { Soakley } \\
\text { Retelling Rubric } \\
\text { Paper plates, fasteners } \\
\text { Prism glasses }\end{array}$ \\
\hline
\end{tabular}




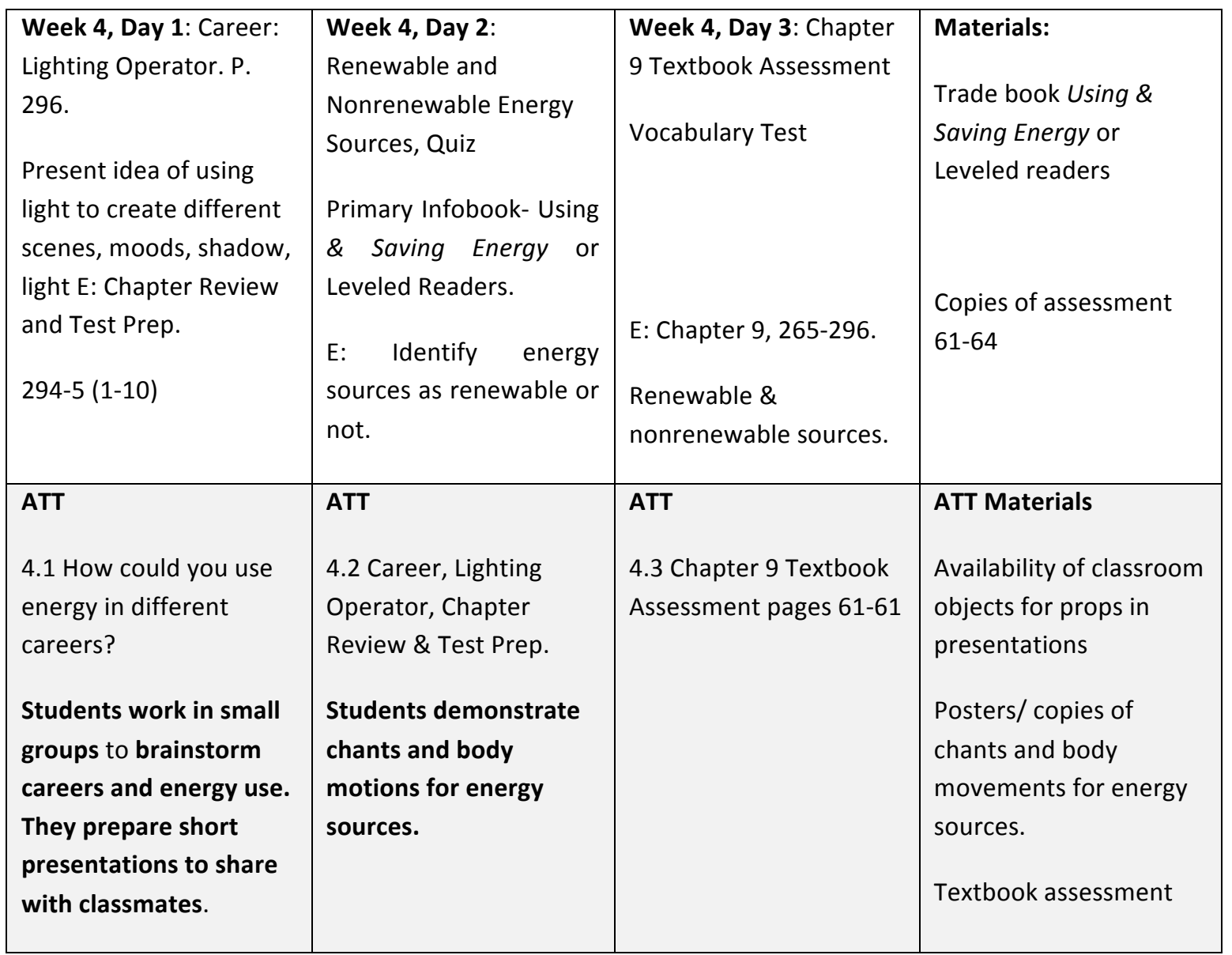

\section{Second Month, 12 lessons, Forces, Motion, \& Magnets}

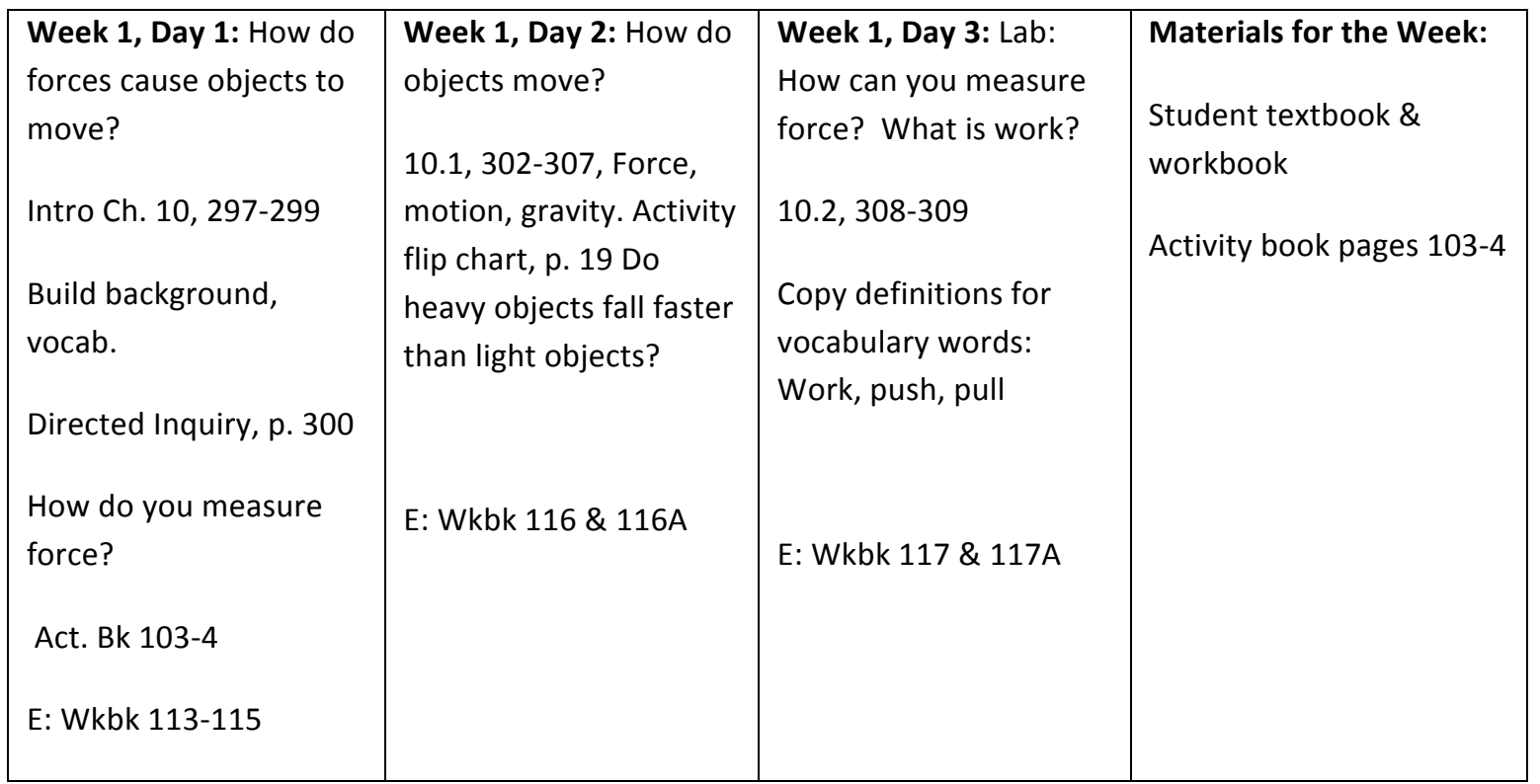




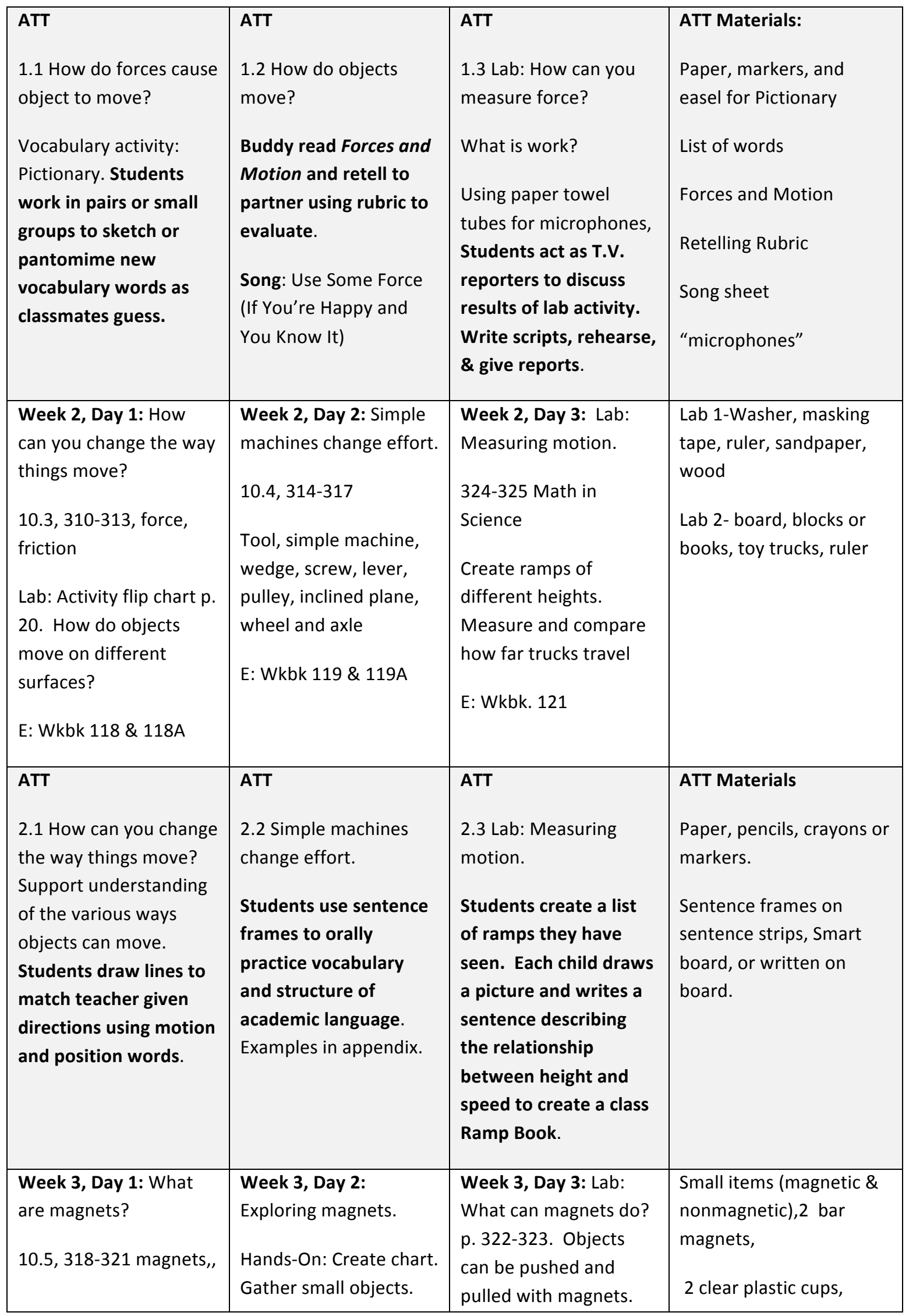




\begin{tabular}{|c|c|c|c|}
\hline $\begin{array}{l}\text { attract, repel, poles } \\
\text { Leveled reader: Magnet } \\
\text { Fun } \\
\text { E: Wkbk } 120 \& 120 \mathrm{~A}\end{array}$ & $\begin{array}{l}\text { Predict and test } \\
\text { whether magnets will } \\
\text { attract an item. Record } \\
\text { on chart. } \\
\text { E: Discussion of results. }\end{array}$ & $\begin{array}{l}\text { What things can they } \\
\text { pull through? Create } \\
\text { chart to predict, test, } \\
\text { record } \\
\text { E: Oral response } \\
\text { interpret data }\end{array}$ & $\begin{array}{l}\text { metal paper clip, water, } \\
\text { paper square }\end{array}$ \\
\hline $\begin{array}{l}\text { ATT } \\
3.1 \text { What are magnets? } \\
\text { To reinforce the } \\
\text { meaning of antonyms, } \\
\text { students act out } \\
\text { directions in which } \\
\text { objects can be pushed } \\
\text { or pulled. Up/down, } \\
\text { near/far, high/low }\end{array}$ & $\begin{array}{l}\text { ATT } \\
\text { 3.2 Exploring magnets. } \\
\text { Students read and } \\
\text { retell NEED booklets in } \\
\text { pairs or small groups } \\
\text { and use the criteria on } \\
\text { Retelling Rubric to } \\
\text { evaluate. }\end{array}$ & $\begin{array}{l}\text { ATT } \\
\text { 3.3 Lab: What can } \\
\text { magnets do? } \\
\text { Divide class into small } \\
\text { groups to give all } \\
\text { students opportunity } \\
\text { to orally report the } \\
\text { results of their } \\
\text { experiment to their } \\
\text { group. }\end{array}$ & $\begin{array}{l}\text { ATT Materials } \\
\text { NEED booklets } \\
\text { Retelling Rubric }\end{array}$ \\
\hline $\begin{array}{l}\text { Week 4, Day 1: Review } \\
\text { and Test Prep. } \\
\text { Review vocabulary and } \\
\text { concepts from force } \\
\text { and motion, properties } \\
\text { of magnets. } \\
\text { E: 326-327, Q. 1-1 }\end{array}$ & $\begin{array}{l}\text { Week 4, Day 2: Career: } \\
\text { Luther Jenkins, } \\
\text { Aerospace Engineer } \\
\text { p. } 328 \text { How he uses } \\
\text { math and science in } \\
\text { work (calculate } \\
\text { distance and speed). E: } \\
\text { Participation in } \\
\text { discussion }\end{array}$ & $\begin{array}{l}\text { Week 4, Day 3: Unit } \\
\text { Test, Forces and } \\
\text { Motion, Magnets. } \\
\text { Textbook assessment } \\
\text { and vocabulary test. } \\
\text { E: Assessment p. 65-68 }\end{array}$ & $\begin{array}{l}\text { Materials } \\
\text { Assessment book p. 65- } \\
68\end{array}$ \\
\hline $\begin{array}{l}\text { ATT } \\
4.1 \text { Review and } \\
\text { Test Prep } \\
\text { Use vocabulary words } \\
\text { force, motion, simple } \\
\text { machine, attract, and } \\
\text { repel. Divide students } \\
\text { into small groups to } \\
\text { create a cheer or chant } \\
\text { using } 1 \text { of the words. }\end{array}$ & $\begin{array}{l}\text { ATT } \\
\text { 4.2 Career: Aerospace } \\
\text { Engineer } \\
\text { Think of career that } \\
\text { involves force and } \\
\text { motion, uses math and } \\
\text { science. } \\
\text { In riddle style, students } \\
\text { prepare } 3 \text { or more clues, } \\
\text { allow classmates to } \\
\text { guess. }\end{array}$ & $\begin{array}{l}\text { ATT } \\
4.3 \text { Textbook } \\
\text { Assessment on Forces } \\
\text { and Motion, Magnets } \\
\text { Pages 65-68. }\end{array}$ & ATT Materials \\
\hline
\end{tabular}




\section{E. Final 2 Weeks}

\begin{tabular}{|l|l|l|l|}
\hline $\begin{array}{l}\text { Administer Post } \\
\text { Tests: }\end{array}$ & $\begin{array}{l}\text { Unit Specific } \\
\text { Vocabulary Tests } \\
\text { National Energy }\end{array}$ & $\begin{array}{l}\text { Collect \& Analyze } \\
\text { Data }\end{array}$ & $\begin{array}{l}\text { Discuss Results, } \\
\text { Conclusions, \& } \\
\text { Implications of Study } \\
\text { Woodcock Muñoz } \\
\begin{array}{l}\text { Enguage Survey- } \\
\text { Revised }\end{array}\end{array}$ \\
$\begin{array}{l}\text { Development Project } \\
\text { (NEED) }\end{array}$ & $\begin{array}{l}\text { for research Q 1 } \\
\text { 2-way covariance for } \\
\text { Research Qs 2 \& 3 }\end{array}$ & \\
\hline
\end{tabular}


The Woodcock-Muñoz Language Survey- Revised (WMLS-R) English forms consist of a set of 7 individually administered tests that provide a broad sampling of proficiency in oral language, language comprehension, reading and writing. The scores from different combinations of these tests provide information regarding an individual's cognitiveacademic language proficiency (CALP) in English. CALP is defined by Cummings (1984) as the aspects of language proficiency that emerge and become distinctive with formal schooling. Because academic learning is usually context-reduced and cognitively demanding, the intent of the WMLS-R is to assess the subject's proficiency with contextreduced and cognitively demanding language. The WMLS-R provides six CALP levels for evaluating competence in listening, speaking, comprehension, reading, writing, and oral language (Alvarado, Ruef, \& Schrank, 2005).

Below is a chart detailing the Academic Language Clusters assessed using the 7 WMLS-R tests.

\begin{tabular}{|c|c|c|c|c|c|c|c|c|}
\hline \multirow{12}{*}{ 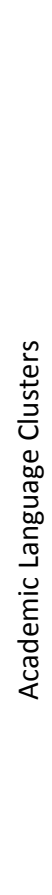 } & WMLS-R Tests & $\begin{array}{l}1 . \\
\text { Picture } \\
\text { vocabu- } \\
\text { lary }\end{array}$ & $\begin{array}{l}2 . \\
\text { Verbal } \\
\text { analogie } \\
\mathrm{s}\end{array}$ & $\begin{array}{l}3 . \\
\text { Letter- } \\
\text { word } \\
\text { identifica- } \\
\text { tion }\end{array}$ & $\begin{array}{l}4 . \\
\text { Dictation }\end{array}$ & $\begin{array}{l}5 . \\
\text { Understanding } \\
\text { directions }\end{array}$ & $\begin{array}{l}6 . \\
\text { Story } \\
\text { recall }\end{array}$ & $\begin{array}{l}7 . \\
\text { Passage } \\
\text { comprehension }\end{array}$ \\
\hline & Oral Language & $x$ & $x$ & & & & & \\
\hline & $\begin{array}{l}\text { Reading- } \\
\text { Writing }\end{array}$ & & & $x$ & $x$ & & & \\
\hline & $\begin{array}{l}\text { Broad English } \\
\text { Ability }\end{array}$ & $x$ & $x$ & $x$ & $x$ & & & \\
\hline & Listening & & $x$ & & & $x$ & & \\
\hline & Oral Exposition & $x$ & & & & & $x$ & \\
\hline & Reading & & & $x$ & & & & $\mathrm{x}$ \\
\hline & Writing & & & & $x$ & & & \\
\hline & $\begin{array}{l}\text { Language } \\
\text { comprehension }\end{array}$ & & & & & & $x$ & $x$ \\
\hline & $\begin{array}{l}\text { Applied } \\
\text { Language } \\
\text { proficiency }\end{array}$ & & & & $x$ & $x$ & $x$ & $x$ \\
\hline & $\begin{array}{l}\text { Oral Language } \\
\text { Total }\end{array}$ & $x$ & $x$ & & & $x$ & $x$ & \\
\hline & $\begin{array}{l}\text { Broad English } \\
\text { ability total }\end{array}$ & $x$ & $x$ & $x$ & $x$ & $x$ & $x$ & $x$ \\
\hline
\end{tabular}


Appendix C

Teacher Instruction Strategy Survey

Name

Grade

Date

Which subjects do you teach?

Reading/Language Arts ___ Math __ Science ___ Social Science

What strategies do you use in teaching these subjects?

Reading/Language Arts

Math

Science

Social Science 
Teacher Instruction Fidelity Checklist

Name Unit

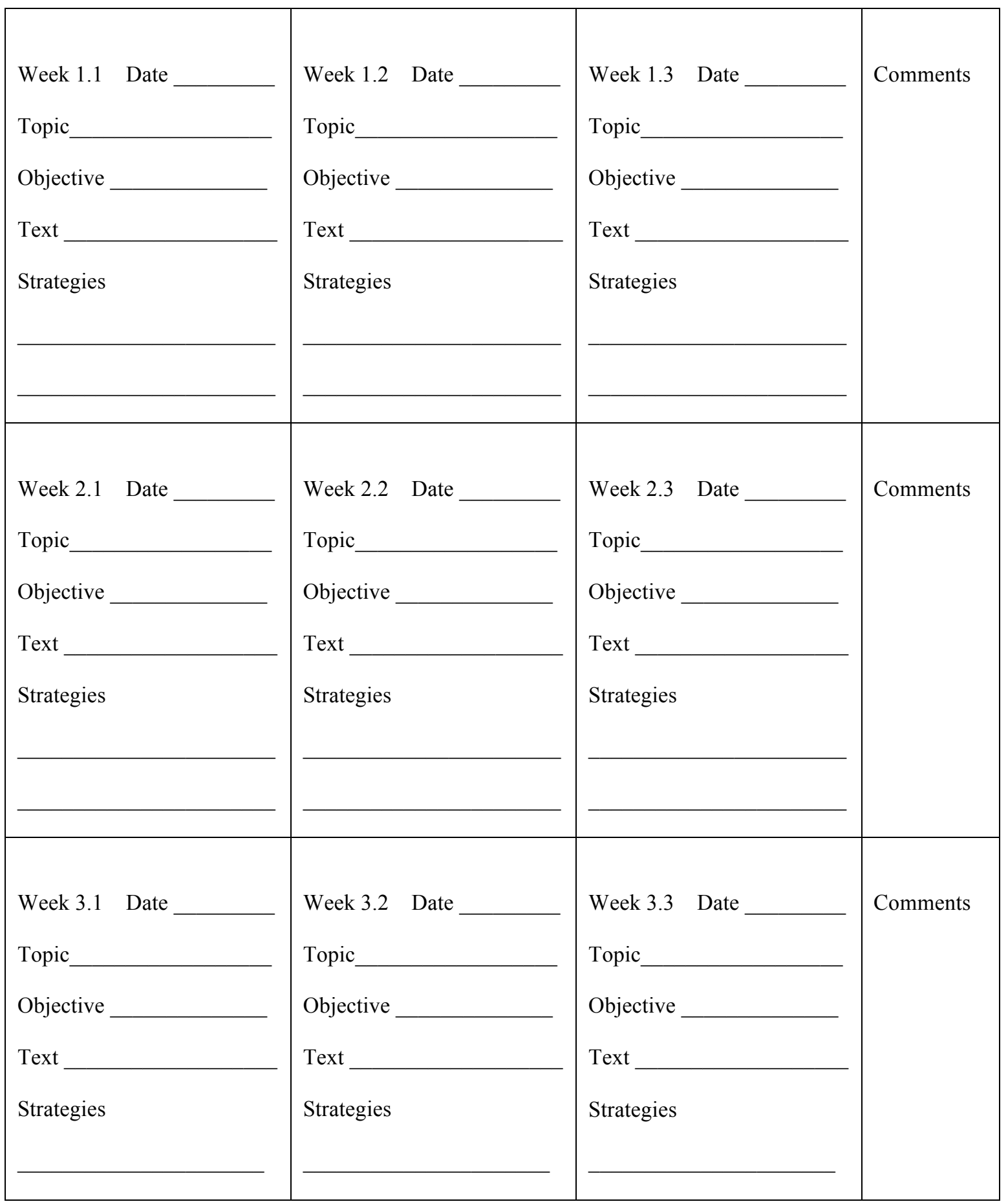




\begin{tabular}{|c|c|c|c|}
\hline Week 4.1 Date & Week 4.2 Date & Week 4.3 Date & Comments \\
\hline Topic & Topic & Topic_ & \\
\hline Objective & Objective & Objective & \\
\hline Text & Text & Text & \\
\hline Strategies & Strategies & Strategies & \\
\hline
\end{tabular}

Teacher Instruction Fidelity Checklist

Name Unit

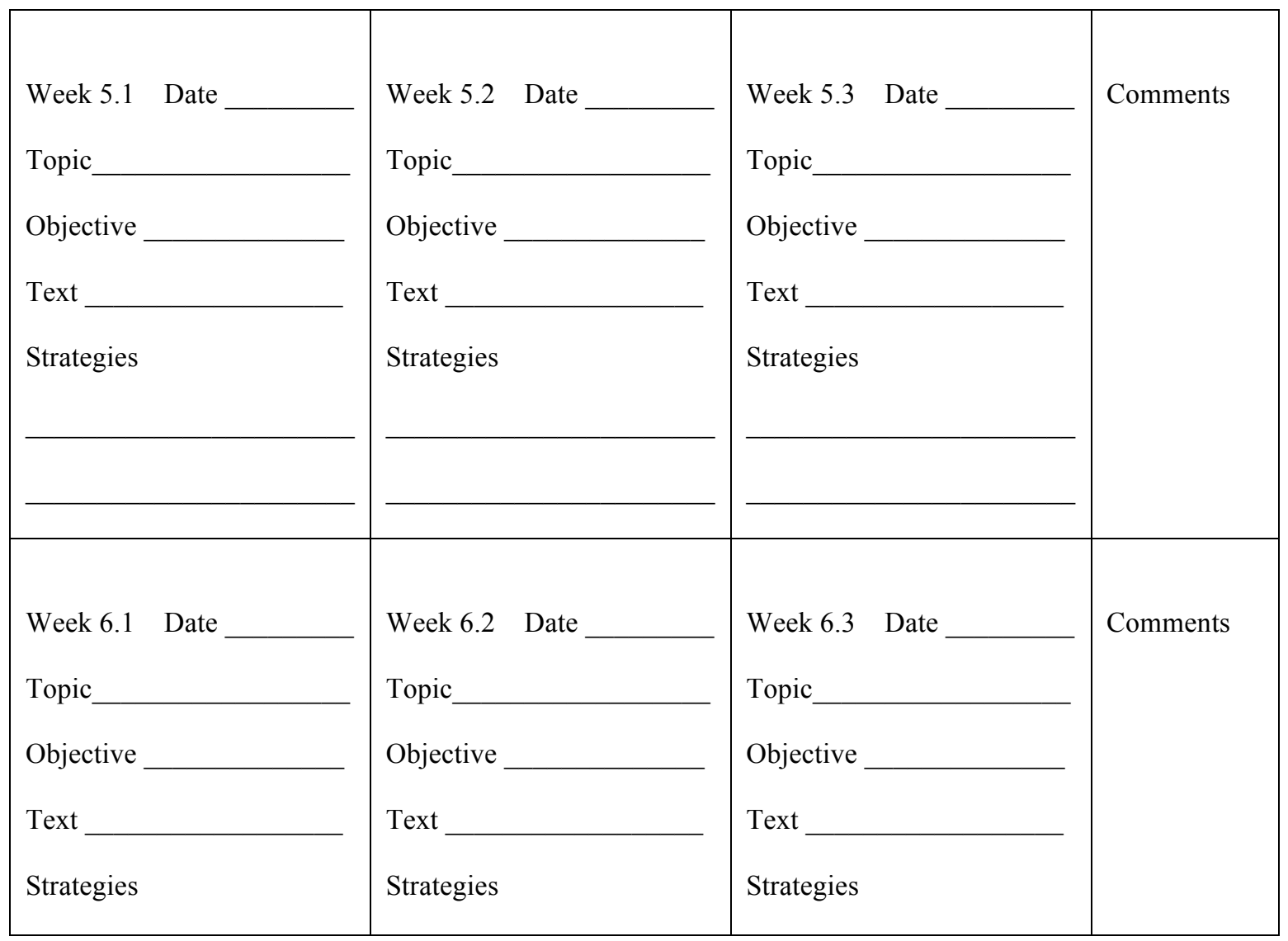




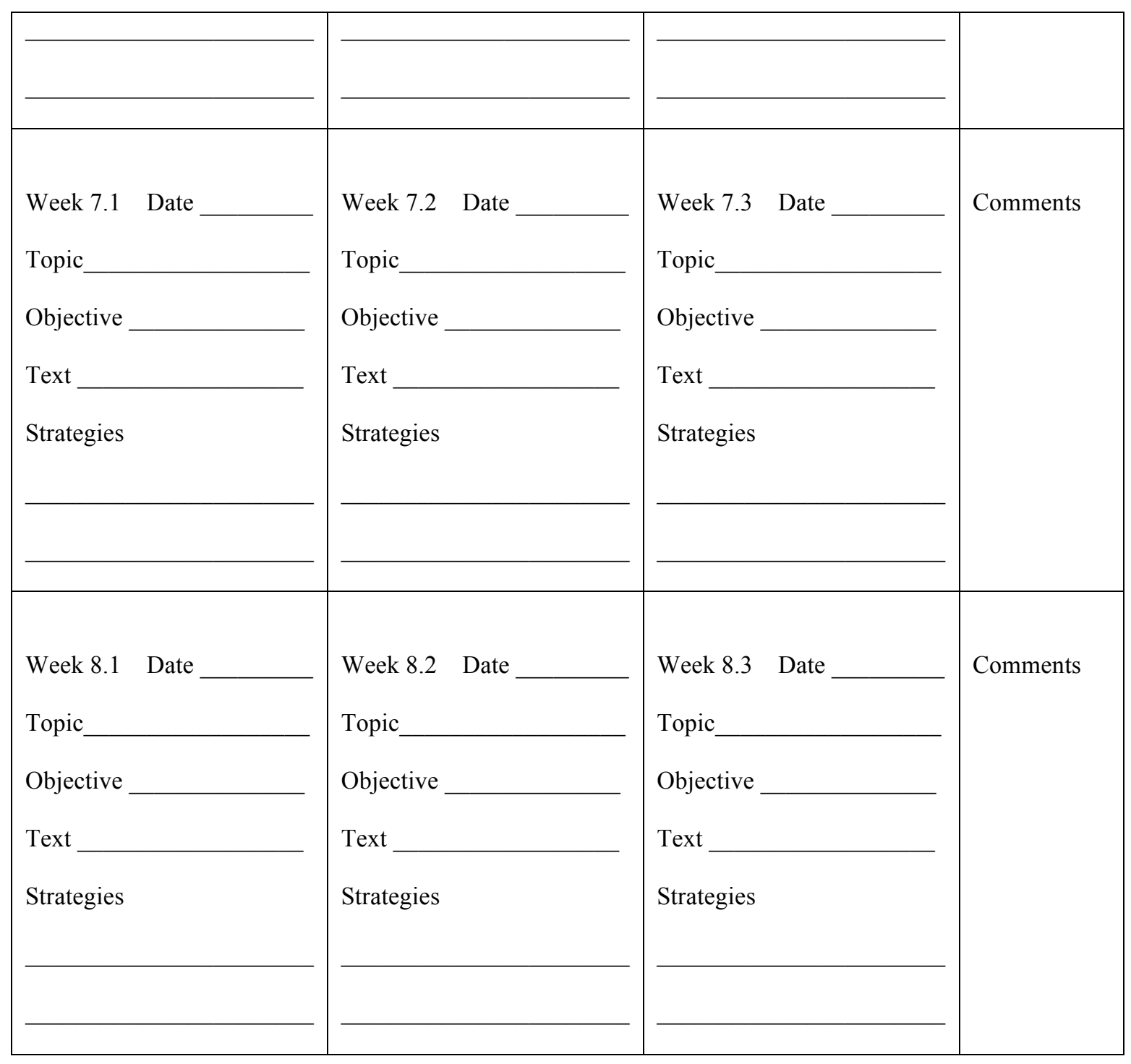


Teacher Instruction Fidelity Checklist: Academic Text Talk

Name Unit

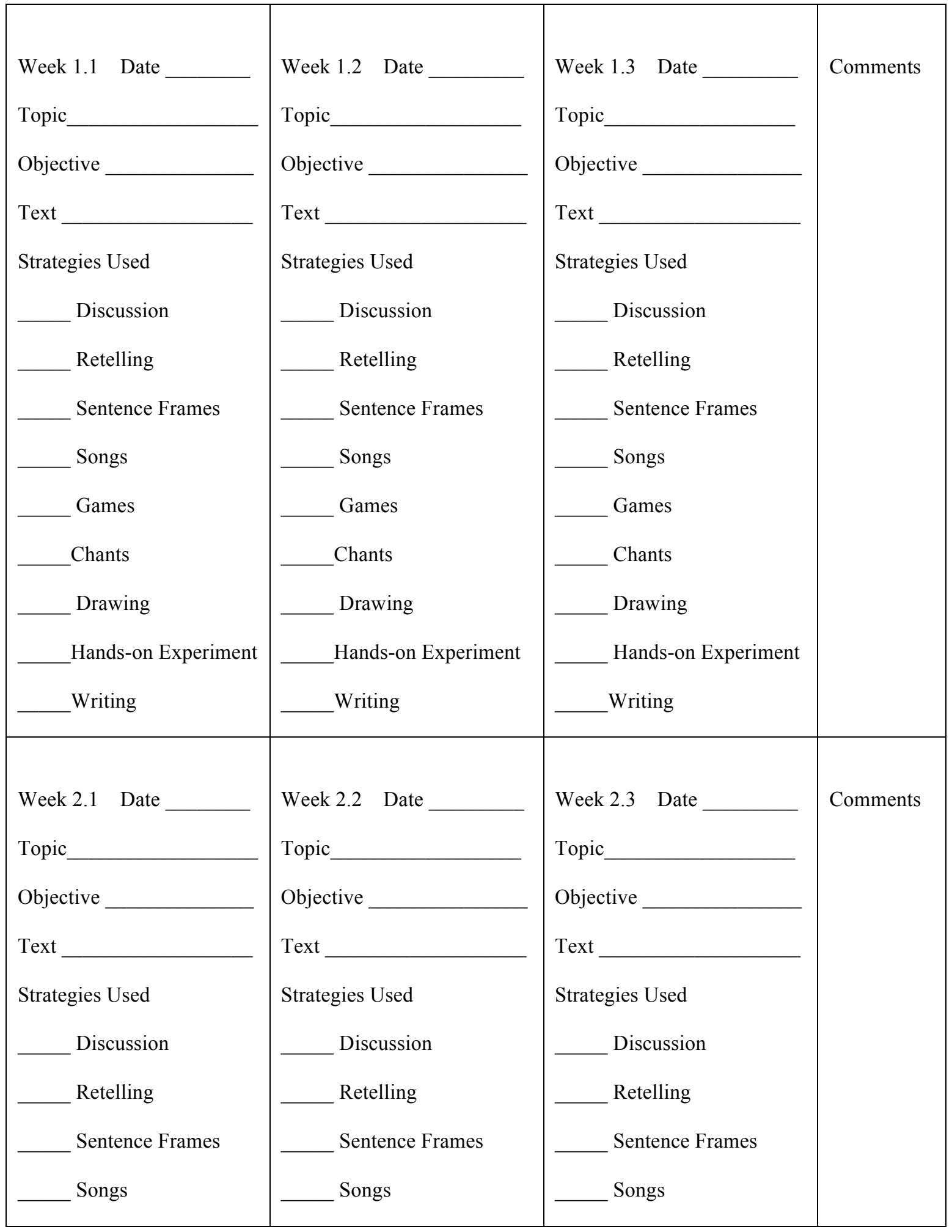




\begin{tabular}{|c|c|c|c|}
\hline _ Games & Games & Games & \\
\hline Chants & Chants & Chants & \\
\hline Drawing & Drawing & Drawing & \\
\hline _Hands-on Experiment & Hands-on Experiment & _Hands-on Experiment & \\
\hline _Writing & Writing & __ Writing & \\
\hline Week 3.1 Date & Week 3.2 Date & Week 3.3 Date & Comments \\
\hline Topic & Topic & Topic & \\
\hline Objective & Objective & Objective & \\
\hline Text & Text & Text & \\
\hline Strategies Used & Strategies Used & Strategies Used & \\
\hline _ Discussion & Discussion & __ Discussion & \\
\hline Retelling & Retelling & Retelling & \\
\hline Sentence Frames & Sentence Frames & Sentence Frames & \\
\hline Songs & Songs & Songs & \\
\hline Games & Games & _ Games & \\
\hline Chants & Chants & Chants & \\
\hline Drawing & Drawing & Drawing & \\
\hline _Hands-on Experiment & _Hands-on Experiment & _Hands-on Experiment & \\
\hline Writing & Writing & _Writing & \\
\hline Week 4.1 Date & Week 4.2 Date & Week 4.3 Date & Comments \\
\hline Topic & Topic & Topic & \\
\hline Objective & Objective & Objective & \\
\hline Text & Text & Text & \\
\hline Strategies Used & Strategies Used & Strategies Used & \\
\hline _ Discussion & Discussion & Discussion & \\
\hline Retelling & Retelling & Retelling & \\
\hline
\end{tabular}




\begin{tabular}{|c|c|c|}
\hline Sentence Frames & Sentence Frames & Sentence Frames \\
\hline Songs & Songs & Songs \\
\hline Games & Games & Games \\
\hline Chants & Chants & Chants \\
\hline Drawing & Drawing & Drawing \\
\hline Hands-on Experiment & _Hands-on Experiment & _Hands-on Experiment \\
\hline Writing & Writing & Writing \\
\hline
\end{tabular}

Teacher Instruction Fidelity Checklist: Academic Text Talk

Name Unit

\begin{tabular}{|c|c|c|c|}
\hline Week 5.1 Date & Week 5.2 Date & Week 5.3 Date & Comments \\
\hline Topic_ & Topic & Topic & \\
\hline Objective & Objective & Objective & \\
\hline Text & Text & Text & \\
\hline Strategies Used & Strategies Used & Strategies Used & \\
\hline _ Discussion & _ Discussion & Discussion & \\
\hline Retelling & Retelling & Retelling & \\
\hline Sentence Frames & Sentence Frames & Sentence Frames & \\
\hline Songs & Songs & Songs & \\
\hline Games & Games & Games & \\
\hline Chants & Chants & Chants & \\
\hline _Drawing & Drawing & Drawing & \\
\hline Hands-on Experiment & Hands-on Experiment & Hands-on Experiment & \\
\hline Writing & _Writing & Writing & \\
\hline
\end{tabular}




\begin{tabular}{|c|c|c|c|}
\hline Week 6.1 Date & Week 6.2 Date & Week 6.3 Date & Comments \\
\hline Topic & Topic & Topic & \\
\hline Objective & Objective & Objective & \\
\hline Text & Text & Text & \\
\hline Strategies Used & Strategies Used & Strategies Used & \\
\hline __ Discussion & __ Discussion & $\ldots$ Discussion & \\
\hline Retelling & Retelling & Retelling & \\
\hline Sentence Frames & Sentence Frames & Sentence Frames & \\
\hline Songs & Songs & Songs & \\
\hline Games & Games & Games & \\
\hline Chants & Chants & Chants & \\
\hline __ Drawing & Drawing & __ Drawing & \\
\hline _Hands-on Experiment & __ Hands-on Experiment & $\ldots$ Hands-on Experiment & \\
\hline W Writing & _Writing & Writing & \\
\hline Week 7.1 Date & Week 7.2 Date & Week 7.3 Date & Comments \\
\hline Topic & Topic & Topic & \\
\hline Objective & Objective & Objective & \\
\hline Text & Text & Text & \\
\hline Strategies Used & Strategies Used & Strategies Used & \\
\hline __ Discussion & _ Discussion & _ Discussion & \\
\hline Retelling & Retelling & Retelling & \\
\hline __ Sentence Frames & Sentence Frames & Sentence Frames & \\
\hline Songs & Songs & Songs & \\
\hline Games & Games & _ Games & \\
\hline Chants & Chants & Chants & \\
\hline Drawing & Drawing & Drawing & \\
\hline
\end{tabular}




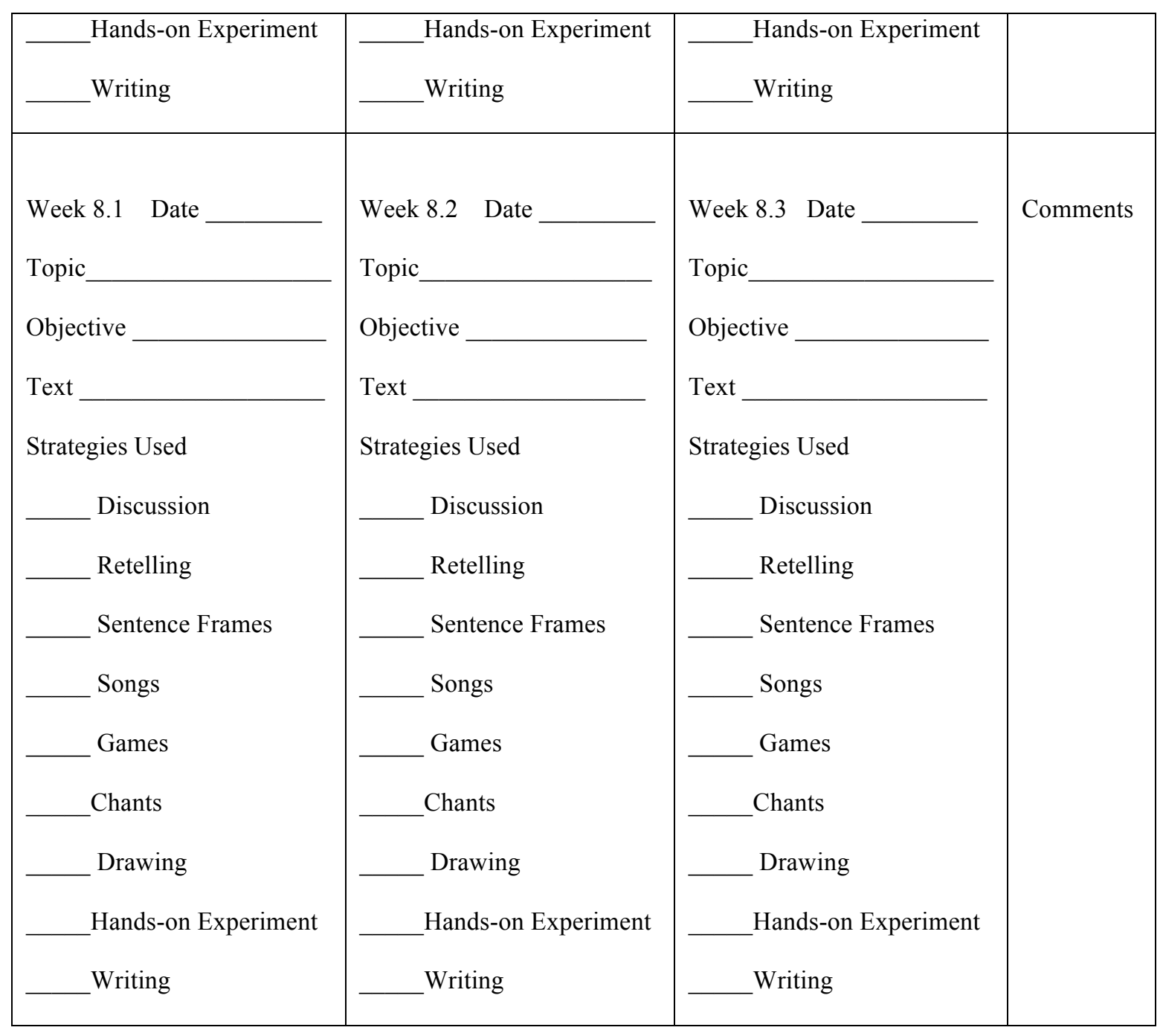


VITA

Peggy Lee Mandel

Born: Morris, Minnesota

1970-1974

A.A, Psychology

University of Minnesota

Minneapolis, Minnesota

1991-1994

B.S., Magna Cum Laude, Education

Florida International University

Miami, Florida

1994-Present

Teacher

Ruth K. Broad Bay Harbor K-8 Center

Bay Harbor Islands, Florida

$1998-2001$

M.S., Teaching and Learning

University of Miami

Miami, Florida

2001

National Board Certified Teacher

2007

2011

2011

National Board Certification Renewal

2011

Ed.S., Curriculum and Instruction, Reading

Florida International University

Miami, Florida

$2003-2013$

Ed.D. Candidate, Curriculum and Instruction

Florida International University

Miami, Florida 